\title{
Do spelling variations affect associative and phonological priming by pseudohomophones?
}

\author{
GEORGIJE LUKATELA and M. T. TURVEY \\ University of Connecticut, Storrs, Connecticut \\ and Haskins Laboratories, New Haven, Connecticut
}

\begin{abstract}
A nonword prime can sound like a target word or one of the target's associates, and it can look like either without sounding like either. These pseudohomophones and pseudohomographs can vary in the number of letters shared with the target or its associate. In an associative priming experiment in which targets were named and prime duration was $125 \mathrm{msec}$ within a mask-prime-mask-target sequence, pseudohomophones primed and pseudohomographs did not, with the pseudoassociative priming being only weakly affected by spelling differences. In three further experiments, prime homophony and homography were defined in respect to the target. Prime durations were 125 and $21 \mathrm{msec}$ within a maskprime-mask-target sequence and $57 \mathrm{msec}$ within a mask-prime-target sequence. The superior priming by pseudohomophones was relatively insensitive to spelling. Results are discussed in terms of the phonological coherence hypothesis and the roles for orthographic information implied by the hypothesis.
\end{abstract}

Words that sound alike tend to look alike-more or less. In orthographies shaped by the rule "write as you speak and read as it is written," such as the Turkish alphabet and the Roman and Cyrillic alphabets of SerboCroatian, there is only one letter pattern for a given phoneme pattern. In orthographies that are shaped as much by morphological as by phonological considerations, such as English, several patterns of letters correspond to a given pattern of phonemes. It is possible, therefore, in English to write KODE, COAD, and KOAD as spellings of the word with the phonology $/ \mathrm{kod} /$, which is properly spelled as CODE. When there are different spellings for a word, the question can be raised of their relative capabilities of leading the reader to the word's representation. Intuitively, the proper spelling should be the most capable, simply on the basis of its much greater frequency of occurrence. But what of the other spellings? Is it sufficient that they are identical phonologically, or does the number of letters by which they differ from the proper spelling matter? The answer to the question concerning the number of shared letters has relevance to theories of visual word recognition. For example, in terms of dual-route theory (e.g., Coltheart, 1978; Coltheart \& Rastle, 1994), a positive answer would be compatible with the frequent claim that the lexical route and, therefore, orthographically based processing assumes the leading role. In contrast, any failure to

The present research was supported by National Institute of Child Health and Human Development Grant HD-01994 to Haskins Laboratories. The experiments were designed by G.L. under National Institute of Child Health and Human Development Grant HD-27709. Correspondence concerning this article should be addressed to G. Lukatela or M. T. Turvey, Haskins Laboratories, 270 Crown Street, New Haven, CT 06510 (e-mail: lukatela@uconnvm.uconn.edu)

-Accepted by previous editor, Myron L. Braunstein find an effect of number of shared letters on the ability of a pseudohomophone to activate a word's representation would suggest that the leading role is assumed by the nonlexical route and that phonological codes, rather than orthographic codes, are the major constraints on visual word recognition.

In the present research with English language materials, nonwords are examined as associative primes, in Experiment 1, within the four-field paradigm of mask-primemask-target, as phonological primes, in Experiments 2 and 3, within the four-field paradigm, and as phonological primes, in Experiment 4, within the three-field paradigm of mask-prime-target. In Experiment 1, a nonword prime is homophonic with an associate of a subsequently presented target word; in Experiments 2-4, a nonword prime is homophonic with the subsequently presented target word itself. In all the experiments, the target word has to be named as rapidly as possible. The question concerning the number of shared letters becomes, therefore, the experimental question of whether associative and phonological priming improves with increasing orthographic similarity between the nonwords and their homophonic words.

Recent investigations of visual word recognition in the Serbo-Croatian language have immediate bearing on the issue of spelling similarity. They reveal that the orthographic identity of two letter strings is of less importance to how the letter strings interact within the word recognition system than is phonological identity. Specifically, these investigations show that pseudohomophones can be more effective form primes than are identity primes (Lukatela, Savic, Urosevic, \& Turvey, 1997) and more effective associative primes than are real-word associates (Lukatela, Carello, Savic, Urosevic, \& Turvey, 1998) in the naming and lexical decision tasks. These superior nonword primes were made possible by the partial overlap 
between the Roman and the Cyrillic alphabets (see Lukatela \& Turvey, 1998). Whereas the majority of the letters are peculiar to one or the other alphabet (they are phonologically unique), the overlap is such that certain letters are pronounced the same way in the two alphabets (they are common) and other letters are pronounced differently, depending on whether they are read as Roman or Cyrillic (they are phonologically ambiguous). Depending on how these letters are combined, letter strings can be formed that have one or more phonological interpretations. Importantly, experiments have shown that all of the phonological codes supportable by a Serbo-Croatian letter string - even those arising from mixing the Roman and Cyrillic codes-are generated in the course of either rapid naming and lexical decision by a reader fluent in both alphabets (e.g., Feldman \& Turvey, 1983; Lukatela, Turvey, Feldman, Carello, \& Katz, 1989). For example, a skilled bi-alphabetic reader appears to be automatically sensitive to the fact that a word such as ROBOT (meaning robot) supports the all-Roman word interpretation / robot /, as well as the mixed-alphabet nonword interpretation / rovot/, because $B$ is pronounced differently in the two alphabets.

This automaticity can be exploited in the creation of pseudohomophones that rely on a mix of alphabets. For example, the nonword letter string РОВОт supports the same two phonological interpretations as ROBOT plus two more - / pobot / and / povot / - because the uniquely Roman $\mathrm{R}$ is replaced by a phonologically ambiguous $\mathrm{P}$. The mixed-alphabet nonword RОБОТ, in contrast, supports only one phonological interpretation, / robot/. Within the four-field presentation sequence of mask-prime-masktarget and with brief prime-target stimulus onset asynchronies (SOAs, e.g., $70 \mathrm{msec}$ ), ROБOT was found to be the most effective form prime for the target word robot (Lukatela et al., 1997) and the most effective associative prime for the target word automat (in English, automaton; Lukatela, Carello, et al., 1998). Although counterintuitive, this superiority in naming and lexical decision for the mixed-alphabet nonword prime (which has never been seen by the reader of Serbo-Croatian) over the identity prime/proper associative prime (which is a common word in the language) was predicted by Lukatela and colleagues on the basis of the phonological coherence hypothesis (Van Orden \& Goldinger, 1994; Van Orden, Pennington, \& Stone, 1990). Because Rовот, unlike RОБот, generates competing phonological patterns, there is insufficient time at short prime-target SOAs for ROBOT to achieve a well-resolved phonological code uniquely able to facilitate the recognition of robot or automat. Importantly, these experiments by Lukatela and colleagues reveal that, with the lengthening of the SOA, form priming and associative priming decrease for the nonword prime RОБОт and increase for the word prime ROBOT.

Among the various accounts that have been offered of the processes underlying the visual recognition of words, the phonological coherence hypothesis seems to stand alone in predicting that, in particular circumstances, a prime identical in orthography and phonology to a given word is not necessarily the ideal prime for that word. An English language approximation to the preceding SerboCroatian studies compares the identity priming for inconsistent words, such as BOwL (which are phonologically ambiguous in the word body), with that for consistent words such as BEND (which are phonologically unambiguous in the word body). The phonological coherence hypothesis predicts that, at very short prime-target SOAs, BOWL may fail to prime itself or, at least, may prime itself much less well than BEND. In contrast, at longer SOAs, BOWL should, like BEND, produce successful identity priming. These predictions hold in both the naming and the lexical decision tasks (Lukatela, Frost, \& Turvey, 1999).

The marked successes of the phonological coherence hypothesis encourage a careful reconceptualization of orthography's contribution to visual word recognition. The contribution can be sought within the adaptive resonance ideas that frame the hypothesis (Grossberg, 1982; Grossberg \& Stone, 1986; Stone \& Van Orden, 1994). With respect to visual word recognition, three adaptive resonances can be identified, each interpretable as the equilibrium state of a fully connected two-layer network with modifiable synaptic weights-namely, visual-phonological, visual-semantic, and phonological-semantic (Stone \& Van Orden, 1994; Van Orden \& Goldinger, 1994). A letter string stimulates a pattern of activity in the input layer common to the visual-phonological and visual-semantic networks that is modified (in the typical weighted-sum fashion) in its transmission to the upper layers. The stimulated phonological pattern will initially include all phonological subpatterns associated with the visual pattern. Competitive-cooperative dynamics within the phonological layer changes the initial phonological activity. They do so in the sense of contrast enhancement - tending to increase the activity of the more appropriate encodings and to decrease (but not fully eliminate) the activity of false encodings arising from crosstalk. The cleaned-up activity pattern at the phonological layer feeds activation back to the visual layer. This top-down activation can be viewed as an attempt by the higher phonological level to interpret the visual pattern (What visual pattern could have produced this phonological pattern?). If the activity pattern excited in the visual input layer is a close match to the pattern excited in the visual input layer by the letter string (i.e., the top-down interpretation was correct), the system is said to be in adaptive resonance. If a match is not achieved, the bottom-up, top-down cycle repeats, with the increased strength of the correct visual pattern providing stronger bottom-up support for the appropriate phonological pattern(s). For a word such as ROSE and for its pseudohomophone ROZE, contrast enhancement and the resonance cycle will eventuate in the elimination of crosstalk and the achievement of equilibrium in the visual-phonological system. That is, processes within the visual-phonological system suffice for phonological coherence. With the further elapse of time, however, the slower visual-semantic resonance results in states of the word-processing system that distinguish ROSE from ROZE. In simpler terms, this 
latter resonance provides a spelling check. Because ROZE is not the orthography of any word, system activity associated with ROZE is suppressed (more precisely, destabilized). The upshot is that, whereas ROzE will, at shorter time scales, function as equivalent to ROSE (e.g., as a prime for flower or as an identity prime), it is not likely to do so at longer time scales. If the effectiveness of visualsemantic resonance in distinguishing words from pseudohomophones depends on the magnitude of the orthographic difference, we might expect the aforementioned suppression of activity to be greater, at some appropriate time scale, for two-letters-different pseudohomophones (e.g., NAIM for NAME) than for one-letter different pseudohomophones (e.g., ROZE for ROSE).

There is another possible way for the orthographic difference between a pseudohomophone and its word to be realized within the processes assumed by the phonological coherence hypothesis. This additional way would operate at the faster time scale of the visual-phonological resonance. Although the bidirectional mappings between the visual and the phonological layers are dictated by the correlations between orthographic subpatterns and phonological subpatterns (see Van Orden \& Goldinger, 1994; Van Orden et al., 1990), crosstalk from the frequent activation of a given phonology by the letter pattern of a given word will induce some small weight variations in the network instantiating orthographic-phonological correspondences at a larger grain size. Thus, for example, the initial and final letters of NAME may come to constitute an orthographic subpattern with a slightly stronger connection to the phonological pattern [nejm] than will the subpattern defined by the initial and final letters of the pseudohomophone NAIM. The consequence would be a slightly faster attainment of visual-phonological resonance in the case of NAME than in the case of NAIM. More generally, the fewer the number of letters shared in the same position between a pseudohomophone and its corresponding word, the slower might be the achievement of phonological coherence by the pseudohomophone, relative to the word.

In sum, the main expectation from the phonological coherence hypothesis is that the orthographic similarity of a prime to a target or of a prime to an associate of the target is of much less importance than phonological similarity. Number of shared letters, therefore, should prove less relevant to the pseudoassociative priming of Experiment 1 and the phonological priming of Experiments 2-4 than are the phonological fits of prime to associate and prime to target, respectively.

\section{EXPERIMENT 1}

The best experimental test of the contribution of spelling to pseudoassociative priming would be through CODE-like words (e.g., Coltheart \& Rastle, 1994). That is, to compare CODE, HODE, KODE, COAD, and KOAD, as primes for the target secret - primes that differ from a major associate of the target by zero, one, one, two, and three let- ters, respectively. Unfortunately, the total number of words capable of producing the preceding pattern of orthographic, phonological, and associative relations is relatively few (approximately 30 ). Consequently, such words can be exploited in an associative priming experiment only as a special subset. The more thoroughgoing test must be carried out on a between-word basis, where adjustments of different words satisfy the homophonic relation between the prime and the target's associate when the prime and the associate differ in either one or two letters.

We examine the associative priming ability of stimuli of the preceding kinds in the rapid-naming task. In Forster's (1990) view, the naming task has a distinct advantage over the lexical decision task where contextual effects are of concern: A detected meaningful relation tells the participant nothing about how to pronounce the target. This contrasts with lexical decision, wherein, as Forster argues, the detection of a meaningful relation between prime and target disposes the participant to infer that the correct response is Yes, because only words can express a meaningful relation. This potentially special virtue of the naming task in studies of associative and semantic priming is not without a major drawback, however. Contextual priming effects in naming tend to be much smaller (often by two to three times) than priming effects in lexical decision (Neely, 1991). For example, Seidenberg, Waters, Sanders, and Langer (1984, Experiment 4) observed semantic and associative effects in naming of 11 and $9 \mathrm{msec}$, respectively, at an SOA of $500 \mathrm{msec}$. In related experiments manipulating various types of word-word relations, Hodgeson (1991) never found an effect in naming in excess of $6 \mathrm{msec}$ across SOAs from 83 to $500 \mathrm{msec}$, and Warren (1977) observed modest effects that increased from 2 to $14 \mathrm{msec}$ as the SOA was lengthened. Experiments comparing associative priming of word naming by appropriate primes and by homophonic nonword primes at prime-target SOAs of $250 \mathrm{msec}$ and longer revealed comparable effects for both prime types of between 11 and $18 \mathrm{msec}$ (e.g., Lukatela \& Turvey, 1991, 1993, 1994a). There are also experimental demonstrations of comparable associative and pseudoassociative priming on the order of 11-13 msec at much shorter prime-target SOAs of 50 and $70 \mathrm{msec}$ (Lukatela \& Turvey, 1994a). In the present experiment, a relatively long prime-target SOA of $250 \mathrm{msec}$ was chosen, in the hope that the priming effects would be sufficiently large to reveal differences owing to spelling differences (if such exist). At the same time, prime processing was restricted to $125 \mathrm{msec}$ by inserting a patterned mask between the prime and the target. The intervening mask was used in order to generalize the earlier observations of pseudoassociative priming with the three-field presentation paradigm (mask-primetarget) to the four-field presentation paradigm (maskprime-mask-target). Minimally, inclusion of the pre- and postprime patterned masks reduces the involvement of overt strategic adjustments (see, e.g., Lesch \& Pollatsek, 1993). 


\section{Method}

Participants. Fifty-six undergraduates at the University of Connecticut participated in the present experiment. A participant was assigned to one of eight counterbalancing groups, according to his or her time of appearance at the laboratory, to give a total of 7 participants per group.

Materials. There were 96 sets of stimuli, with each set consisting of a target and eight primes: an appropriate associative prime (e.g., ROSE, RAIN for the targets flower and wet, respectively), a pseudoassociative prime differing from the appropriate prime by either one or two letters (e.g., ROZE, RANE), a pseudohomographic prime similarly differing from the appropriate prime by either one or two letters (e.g., ROFE, RANS), a dedicated nonword prime sharing no letter in a given position with any of the test primes (e.g., SHIR, YERT), and control primes for each of the associative, pseudoassociative, pseudohomographic, and dedicated nonword primes. One half of the appropriate primes were low-frequency (LF) words, and the other half were high-frequency (HF) words. LF word primes had a mean frequency of $18.69 \pm 11.56$. HF word primes had a mean frequency of $173.73 \pm 155.78$. (All the frequencies were determined from Kučera and Francis, 1967.) One half of the pseudoassociative primes differed from the appropriate prime in one letter, and the other half differed in two letters. A number of the pseudohomophonic primes were actually English words (i.e., they can be found in a standard dictionary), but their frequency of occurrence was zero, according to Kučera and Francis, making them, for all intents and purposes, nonwords in the eyes of the participants. The nonword quality of these particular pseudohomophones was checked in a preceding pilot study with undergraduate students from the same population as that of the participants. The 96 sets of stimuli are shown in Appendix A. ${ }^{1}$

The difficulties in producing individual control primes for each of the test primes under the constraints of the present experimental design should be underscored. In the ideal case, a control prime should (1) not be a prominent associate of the target word, (2) have the same frequency of occurrence as the test prime, (3) have the same number of letters as the test prime, and (4) differ in the nonword cases from its source word by the same number of letters in the same positions that the corresponding nonword test prime differs from its source word. The fourth constraint imposed severe restrictions on the number of choices within the available word materials and within the given number of conditions and enforced exceptions to the general design principles. Possibly the most troublesome exceptions occurred with respect to those stimulus sets (appropriate prime, pseudohomophone prime, pseudohomograph prime, and target) in which the control for the appropriate prime (and the source word for the other control primes) was allowed to be a word that was known to be weakly associated with the target word, as determined from the rankings of associations made by an independent group of University of Connecticut undergraduates to the target words. This particular deviation from the ideal individual control would reduce the degree of associative priming. Accordingly, two analyses were planned: one in which test primes were compared with individualized controls and one in which test primes were compared with a common control and with each other. In the latter case, the appropriate, pseudohomophone, and pseudohomograph primes would be compared against the dedicated nonword prime (e.g., ROSE, ROZE, and ROYE against SHIR and RAIN, RANE, and RANS against YERT) and against each other.

In addition to the major manipulation defined over the preceding 96 sets, there were 24 sets of stimuli conforming to the pattern CODE, HODE, KODE, COAD, and KOAD, as associative primes for the target secret. These are shown in Appendix B. Each priming word in this additional set was chosen under the following constraints: (1) to be 4 or 5 letters in length, (2) to be sufficiently familiar to un- dergraduates to allow a reasonably strong association with a word of less than 10 letters, and (3) to permit the creation of pseudohomophones that had three different degrees of visual overlap with the source word but were necessarily of the same word length as the source word (e.g., CODE vs. KODE, COAD, and KOAD; or SKATE vs. SCATE, SKAIT, and SCAIT). Each pseudohomophone differed from its source word by 1,2 , or 3 letters in the same position. The subsidiary set was matched with 24 associatively related target words, which were determined in a pilot study. Accordingly, the subsidiary set was composed of eight lists: List 1 consisted of 24 appropriate prime-target pairs (e.g., CODE--secret, SCALE-weight); List 2 was obtained by replacing the initial or the second to initial letter of the prime words in List 1, to produce 1-letter-different pseudohomophone primes (e.g., KODE-secret, SKALE-weight); List 3 was an exact duplication of List 2 ; List 4 was created by replacing both final letters of the prime words, to produce 2-letter-different pseudohomophone primes (e.g., COAD-secret, SCAIL-weight); List 5 was an exact duplication of List 4; List 6 was created by replacing I of 2 initial letters and both final letters of the prime words, to produce a 3-lettersdifferent pseudohomophone (e.g., KOAD-secret, SCAIL-weight); List 7 was created by replacing each prime in List 1 by an unrelated nonword constructed by replacing just 1 of 2 initial letters of the source word (e.g., HODE-secret, SPALE-weight); List 8 was created by replacing each prime in List 1 by a control word (e.g., FISH-secret, RIFLE-weight) that was selected under the constraints that it was not a prominent associate of the corresponding target, was of the same length and same frequency of occurrence as the word prime in List 1 , and shared with that word prime no letter in the same position. An attempt to find suitable individualized control stimuli for each individual test prime outside the subsidiary set of 24 CODE-like stimuli did not succeed, owing to the severe constraints imposed by each set of cone-like words.

Design. Eight counterbalanced experimental lists from the major stimulus set of Appendix A were prepared for eight groups of participants. There were 32 experimental conditions formed by the factorial combination of four levels of prime type, two levels of relatedness, two levels of prime frequency, and two levels of orthographic overlap. Altogether, each participant was presented with 96 basic test pairs, 24 subsidiary test pairs, and 18 foil pairs, making a total of 138 stimulus pairs per session. The experimental sequence was divided into three parts, with a brief rest after each part. Stimulus types were ordered pseudorandomly within each participant. The experimental sequence was preceded by a practice sequence of 38 different unrelated stimulus pairs.

Procedure. The participants, run one at a time, sat in front of the CRT of an Apple IIe computer ${ }^{2}$ in a well-lit room. Each trial consisted of an auditory warning signal, followed by a sequence of visual presentations: a pattern mask of 500 -msec duration; a prime of 125-msec duration; a second pattern mask of 125-msec duration; and finally, a target of 400-msec duration. All interstimulus intervals (ISIs) were zero, making the $\mathrm{SOA}=250 \mathrm{msec}$. (Control of stimulus durations and SOAs was made possible by modifications of the machine code of the Apple IIe.) The exposure durations above are average, rather than exact, because display changes, in reality, occurred within the standard 16-msec scan rate of the Apple Ile monitor. This means that all actual durations of nominal exposures varied in a random manner between +8 and $-8 \mathrm{msec}$ around the statistical mean exposure.

Each participant was told that he or she would be viewing on each trial a sequence of two letter strings, with the second letter string being always a word in lowercase, and that his or her task was to name out loud the lowercase word as quickly and as accurately as possible. In all the conditions, latencies from the onset of the target to the onset of the response were measured by a voice-operated trigger relay. Naming was considered erroneous when the target word 
Table 1

Mean Naming Latencies (in Milliseconds) With the Corresponding Standard Deviations by Participants and by Items in Experiment 1

\begin{tabular}{|c|c|c|c|c|c|c|c|c|}
\hline & \multicolumn{2}{|c|}{ Appropriate } & \multicolumn{2}{|c|}{ Pseudohomograph } & \multicolumn{2}{|c|}{ Pseudohomophone } & \multicolumn{2}{|c|}{$\begin{array}{l}\text { Dedicated } \\
\text { Nonword }\end{array}$} \\
\hline & Test & Control & Test & Control & Test & Control & Test & Control \\
\hline \multicolumn{9}{|c|}{ One-Letter-Different Primes } \\
\hline$M$ & 538 & 546 & 560 & 562 & 543 & 555 & 557 & 560 \\
\hline$S D_{1}$ & 62 & 65 & 75 & 71 & 56 & 63 & 64 & 62 \\
\hline$S D_{2}$ & 40 & 47 & 52 & 45 & 38 & 44 & 46 & 37 \\
\hline \multicolumn{9}{|c|}{ Two-Letters-Different Primes } \\
\hline$M$ & 552 & 558 & 562 & 570 & 555 & 568 & 572 & 572 \\
\hline$S D_{1}$ & 70 & 70 & 71 & 68 & 63 & 72 & 70 & 66 \\
\hline$S D_{2}$ & 48 & 47 & 57 & 52 & 47 & 55 & 53 & 49 \\
\hline
\end{tabular}

was mispronounced or preceded by any other sound, the pronunciation was not smooth (i.e., the participant hesitated after beginning to name), or the response was not loud enough to trigger the voice key. If the naming latency was longer than $1 \mathrm{sec}$, a message appeared on the screen after the response, requesting the participant to name more quickly on the next trial. All the latencies, including those longer than $1 \mathrm{sec}$, were stored in the computer memory.

In the experiments of Lukatela and Turvey (1994a), a trimming procedure of \pm 2 standard deviations ( $S D s$ ) had been used. Given recent concerns over truncations of data sets in reaction time analyses (Ulrich \& Miller, 1994; Van Selst \& Jolicoeur, 1994), the truncation based on $S D$ was abandoned, and the data entered into the present analysis excluded less than $0.5 \%$ (see Ulrich \& Miller, 1994, p. 69). Given an incomplete theory of processing, it seems imprudent to include all the responses, given that latencies of 2-3 sec and above are not likely to be tapping the same mechanisms as those responsible for naming latencies in the vicinity of $400-500 \mathrm{msec}$. The $0.5 \%$ cutoff was easily satisfied by the range of $100-1,400 \mathrm{msec}$. Within this range, almost all the correct responses were included, so that, when the outliers and true naming errors were summed, the mean number of excluded responses amounted to $0.6 \%$. (In Experiments 2 and 3 , the mean was $0.66 \%$ and $0.76 \%$, respectively.)

\section{Results}

Table 1 presents the mean latencies and standard deviations for the major stimulus set of Appendix A. Table 2 presents the corresponding summary for the subsidiary stimulus set of Appendix B. An analysis of the test primes was done (1) with respect to their individual controls and (2) with respect to the dedicated nonword and to each other.

Analysis based on comparisons of test primes with individual controls. A $4 \times 2 \times 2 \times 2$ (prime type $\times$ relatedness $\times$ prime frequency $\times$ letter difference) analysis of variance (ANOVA) based on 56 participants and 96 stimulus pairs was conducted. Only prime frequency is a real variable; the other factors in the ANOVA are quasivariables. Thus, prime type refers to the four groupings within each set of eight stimuli defined by the appropriate word and its control, the pseudohomograph and its control, the pseudohomophone and its control, and the dedicated nonword and its control. Likewise, the relatedness factor refers to the contrast between the test primes (where the word prime, which is the source of the nonword test primes, is an associate of the target) and the control primes (where the word prime, which is the source of the nonword test primes, is not an associate of the target). And finally, the factor of letter difference refers to the stimulus sets built around the requirement of constructing a pseudohomophone differing (1) in one letter from the appropriate prime and (2) in two letters from the appropriate prime. Prime type was reliable $\left[F_{1}(3,165)=14.06, p<.001 ; F_{2}(3,276)=\right.$ $14.62, p<.001]$. Relatedness was reliable $\left[F_{1}(1,55)=\right.$ $\left.17.33, p<.001 ; F_{2}(1,92)=4.06, p<.05\right]$, and letter difference (one letter $=553 \mathrm{msec}$ vs. two letters $=563 \mathrm{msec}$ ) was reliable by participants $\left[F_{1}(1,55)=50.82, p<.001\right]$, but not by stimuli $\left[F_{2}(1,92)=2.24, p>.10\right]$. No other main effects and none of the interactions was reliable.

Planned comparisons revealed that the 7-msec difference between appropriate primes (e.g., ROSE, RAIN) and their individual controls (DEAL, NAME) was reliable by participants $\left[F_{1}(1,55)=5.98, p<.02\right]$, but not by items $\left[F_{2}(1,92)=1.69, p>.05\right]$. In contrast, the $13-\mathrm{msec}$ difference between pseudohomophones (e.g., ROZE, RANE) and their individual controls (DEEL, NAIM) was reliable by both analyses $\left[F_{1}(1,55)=18.06, p<.001 ; F_{2}(1,92)=\right.$ $6.72, p<.01]$. The 5 -msec difference between pseudohomographs (e.g., ROYE, RANS) and their individual controls (DERL, NALM) was not reliable $\left[F_{1}(1,55)=2.65, p>\right.$ $\left..05 ; F_{2}(1,92)<1\right]$. Similarly unreliable was the $3-\mathrm{msec}$ difference between the dedicated nonwords (e.g., SHIR, YERT) and their individual controls (NITH, PUNG; both $F$ s $<1$ ). Of the partial interactions, only that involving pseudohomophones and dedicated nonwords was reliable $\left[F_{1}(1,55)=5.79, p<.05 ; F_{2}(1,92)=3.86, p<.05\right]$.

Important planned comparisons are those dealing with the one-letter and two-letter differences. These suggested that the two classes of pseudohomophones were reliable to the same degree [one-letter-different primes (13-msec advantage): $F_{1}(1,55)=9.68, p<.01 ; F_{2}(1,46)=3.16, p=$ .08; two-letters-different primes (14-msec advantage): $\left.F_{1}(1,55)=10.72, p<.01 ; F_{2}(1,46)=3.56, p=.07\right]$.

Analysis based on comparisons among test primes. A $4 \times 2 \times 2$ (prime type $\times$ prime frequency $\times$ letter difference) ANOVA was conducted, with the factors 
Table 2A

Mean Naming Latencies (in Milliseconds) With

the Corresponding Standard Deviations by Participants

for the "CODE-Like" Primes in Experiments 1-3:

Base Word and One-Letter-Different Nonwords

\begin{tabular}{|c|c|c|c|c|c|c|c|c|}
\hline \multirow[b]{2}{*}{ Experiment } & \multicolumn{2}{|c|}{ CODE } & \multicolumn{2}{|c|}{ KODE (1) } & \multicolumn{2}{|c|}{ KODE (2) } & \multicolumn{2}{|c|}{ HODE } \\
\hline & $M$ & $S D$ & $M$ & $S D$ & $M$ & $S D$ & $M$ & $S D$ \\
\hline 1 & 531 & 56 & 540 & 60 & 542 & 67 & 556 & 80 \\
\hline 2 & 527 & 62 & 559 & 67 & 553 & 69 & 588 & \\
\hline 3 & 543 & 69 & 558 & 71 & 562 & 81 & 576 & 71 \\
\hline
\end{tabular}

Note-.Parenthesized numbers in table subheadings refer to the repetition of prime condition within the experimental design.

following from the definitions given above. Prime type was highly significant $\left[F_{1}(3,165)=12.45, p<.001\right.$; $\left.F_{2}(3,276)=8.71, p<.001\right]$. The mean latency to the stimulus set involving one-letter-different primes $(548 \mathrm{msec})$ was significantly shorter than the mean latency to the stimulus set involving two-letter-different primes [557 $\mathrm{msec}$; $\left.F_{1}(1,55)=15.50, p<.001 ; F_{2}(1,92)=4.93, p<.05\right]$. No other main effect or interaction reached significance.

Planned comparisons were conducted. The $19-\mathrm{msec}$ difference between the appropriate primes and the dedicated nonword primes was reliable $\left[F_{1}(1,55)=23.60\right.$, $\left.p<.001 ; F_{2}(1,92)=15.78, p<.001\right]$, as was the $16-\mathrm{msec}$ benefit of appropriate primes over pseudohomographic primes $\left[F_{1}(1,55)=20.48, p<.001 ; F_{2}(1,92)=13.96\right.$, $p<.001]$. The 3-msec difference between the pseudohomographic primes and the dedicated nonword primes was not significant (both $F \mathrm{~s}<1$ ), but the 16-msec difference between pseudohomophone primes and the dedicated nonword primes was significant $\left[F_{1}(1,55)=17.58\right.$, $\left.p<.001 ; F_{2}(1,92)=12.50, p<.001\right]$. Importantly, the 12msec difference favoring pseudohomophone primes over pseudohomographic primes was significant $\left[F_{1}(1,55)=\right.$ $\left.8.99, p<.01 ; F_{2}(1,92)=10.16, p<.01\right]$, whereas the -4-msec difference between pseudohomophonic and appropriate primes was not (both $F \mathrm{~s}<1$ ).

The latter important facts were supported by both the one-letter- and the two-letters-different pseudohomophonic primes: ROZE-flower was significantly faster than SHIR-flower by $14 \mathrm{msec}\left[F_{1}(1,55)=11.37, p<.001\right.$; $\left.F_{2}(1,46)=7.64, p<.01\right]$ and insignificantly slower than ROSE-flower by $4 \mathrm{msec}$ (both $F \mathrm{~s}<1$ ); RANE-wet was significantly faster than YERT-wet by $17 \mathrm{msec}\left[F_{1}(1,55)=\right.$ $\left.9.07, p<.01 ; F_{2}(1,46)=5.73, p<.05\right]$ and insignificantly slower than RAIN-wet by $2 \mathrm{msec}$ (both $F \mathrm{~s}<1$ ). Diluting the conclusion that one-letter-different and twoletters-different primes were functionally equivalent is the outcome of the analysis involving the corresponding pseudohomographs. Whereas one-letter-different pseudohomophones were significantly different from one-letterdifferent pseudohomographs $\left[17 \mathrm{msec} ; F_{1}(1,55)=11.36\right.$, $\left.p<.001 ; F_{2}(1,46)=8.59, p<.01\right]$, two-letters-different pseudohomophones were not significantly different from two-letters-different pseudohomographs $\left[7 \mathrm{msec} ; F_{1}(1,55)\right.$ $\left.=1.84, p>.05 ; F_{2}(1,46)<1\right]$.

Analysis of CoDE-like stimuli. Because this subsidiary set of stimuli was close to exhaustive, analysis was lim- ited to participants. An ANOVA revealed a main effect of prime type $\left[F_{1}(7,385)=2.23, p<.05\right]$. The planned comparisons confirmed that appropriate priming occurred: The 13-msec advantage of CODE over FISH and the $25-\mathrm{msec}$ difference between CODE and HODE were both reliable $\left[F_{1}(1,385)=3.76, p<.05\right.$, and $F_{1}(1,385)=14.40, p<$ .001 , respectively]. Given that KODE and COAD were embodied in the experiment twice (see the Design section and Table 2), the longer mean latencies were used in the subsequent comparisons. The 14-msec difference that favored KODE over HODE was reliable $\left[F_{1}(1,385)=4.58\right.$, $p<.05]$, as was the 14-msec difference favoring COAD over HODE $\left[F_{1}(1,385)=3.99, p<.05\right]$. Importantly, there was a reliable 14-msec advantage for KOAD over HODE $\left[F_{1}(1,385)=4.13, p<.05\right]$. None of the three types of pseudohomophone primes differed, however, from either CODE or FISH $(p>.05)$, and the 12-msec superiority of FISH over HODE was not reliable $\left[F_{1}(1,385)=3.44, p>.05\right]$.

\section{Discussion}

The degree of associative priming by appropriate primes within the major stimulus set depended on the analysis. For the analysis involving individualized controls it was relatively weak $(7 \mathrm{msec}$, significant only by participants). The unavoidable inclusion of some appropriate prime controls that had associations to the targets (see the Method section) seems to have obscured the facilitating effect of the appropriate primes. For the analysis involving just the test primes, the associative priming by appropriate primes was strong $(19 \mathrm{msec}$, significant by participants and by items). The sizes of the appropriate associative priming effects under both analyses fit the range of small but reliable magnitudes typically observed in the rapid-naming procedure, as was reviewed in the introduction to Experiment 1.

Turning to the observations on the nonword primes, if priming was restricted to orthographic forms, it might be expected that RANE should prime wet less well than ROZE should prime flower, because RANE has fewer letters in common (in identity and position) with the appropriate prime RAIN than ROZE has with the appropriate prime ROSE. The results with the major stimulus set of Experiment 1 (in both the analysis with individual controls and the analysis restricted to test primes) suggest, to the contrary, that the two nonword homophonic primes were equally effective in bringing about associative priming and did

Table 2B

Mean Naming Latencies (in Milliseconds) With the Corresponding Standard Deviations by Participants for the "CODE-Like" Primes in Experiments 1-3: Control Word and Two- and Three-Letters-Different Nonwords

\begin{tabular}{|c|c|c|c|c|c|c|c|c|}
\hline \multirow[b]{2}{*}{ Experiment } & \multicolumn{2}{|c|}{ FISH } & \multicolumn{2}{|c|}{$\operatorname{COAD}(1)$} & \multicolumn{2}{|c|}{$\operatorname{COAD}(2)$} & \multicolumn{2}{|c|}{ KOAD } \\
\hline & $M$ & $S D$ & $M$ & $S D$ & $M$ & $\overline{S D}$ & $M$ & $S D$ \\
\hline 1 & 544 & 61 & 538 & 54 & 543 & 56 & 542 & 65 \\
\hline 2 & 582 & 66 & 547 & 66 & 554 & 72 & 557 & 66 \\
\hline 3 & 568 & 69 & 547 & 69 & 552 & 69 & 558 & 68 \\
\hline
\end{tabular}

Note-Parenthesized numbers in table subheadings refer to the repetition of prime condition within the experimental design. 
not differ in this respect from the appropriate prime itself. In addition, if priming was restricted to orthographic forms, RANE would prime wet no better than RANS would prime wet, given that both differ from RAIN in two letters. The results suggest, to the contrary, that RANE produced effective pseudoassociative priming, whereas RANS did not. With some qualification, similar conclusions follow from the results with the subsidiary set of stimuli. If priming was restricted to orthographic forms, KOAD would prime secret worse than HODE would prime secret, given that HODE has only one letter different from the appropriate prime CODE and that KOAD has only one letter in common with the appropriate prime CODE. It was observed, to the contrary, that KOAD led to faster naming than HODE. The latter observation must be treated circumspectly, however, given that none of the pseudohomophone primes differed from the control FISH. That is, strictly speaking, there were no pseudoassociative priming effects in the subsidiary stimuli.

In sum, the several analyses of Experiment 1, particularly those conducted on the major stimulus set, were consistent with the hypothesis that pseudoassociative priming is due primarily to the shared phonology, rather than to the shared orthography, of the nonword prime and the associate of the target. The one disqualifier of this latter conclusion is the absence of a significant difference between two-letters-different pseudohomophones and their corresponding two-letters-different pseudohomographs.

One point of additional significance should be noted. The pattern of reported results derived from the ANOVAs and planned comparisons above were reproduced when the analyses were conducted on the data trimmed according to the two $S D$ convention (a fact that held true, in addition, for the outcomes of Experiments 2-4).

\section{EXPERIMENT 2}

From the perspective of dual-route theory (classical and modern), if a prime is phonologically similar to its target, processing the target can benefit, in principle, from the prior application of grapheme-phoneme correspondence rules (priming the nonlexical route), the prior activation of phonological lexical neighbors (priming the lexical route), or both. An early and theoretically important investigation of phonological priming in English was conducted by Humphreys, Evett, and Taylor (1982). Their focus was the issue of whether phonological codes are determined automatically and, if they are, whether the lexical or the nonlexical route is responsible. In two experiments, Humphreys et al. demonstrated an automatic priming between homophonically related words. The demonstration used a stimulus sequence of pattern maskprime-target-pattern mask and a target identification task. Homophonic word pairs were found to produce more correct identifications than did their graphemic controls. The inference of automaticity was based on the brevity of the target (approximately $35 \mathrm{msec}$, on the average) and the unlikelihood of conscious strategies (such as expecting a stimulus that sounds like the prime), given the masking procedure. In order to evaluate whether this fast, automatic priming on phonological dimensions was conveyed over the lexical or the nonlexical route, Humphreys et al. ran the experiment with pseudohomophone primes that, in theory, can only be processed by the nonlexical route. Humphreys et al. found no priming by pseudohomophones. On the basis of this negative outcome, they concluded that the successful homophonic priming must have been due to automatic addressed (lexical) phonology and that the unsuccessful priming with pseudohomophones must be indicative of an assembled (nonlexical) phonology that is (1) strategic rather than automatic, (2) slow relative to addressed phonology, or (3) nonexistent.

Recent experiments have been more successful in demonstrating the priming of words (e.g., toad) by homophonic but orthographically dissimilar nonwords (e.g., TODE) over a range (34-250 msec) of nonword-word onset asynchronies (e.g., Lukatela \& Turvey, 1994b). In these experiments, using rapid naming rather than identification, the target was not followed by a mask, so that it could be responded to with minimal error. An important observation was that, at the shorter prime-target SOAs, but not at the longer prime-target SOAs, the insertion of a patterned mask between the (forwardly masked) prime and the target was necessary for obtaining a pseudohomophonic priming (e.g., TODE-toad) effect that exceeded priming by nonhomophonic nonwords of similar orthography (e.g., TODS). One reading of this outcome is that orthographic priming is limited to very short SOAs, arising from briefly persisting activity in the input layer of visual features. Consequently, with the insertion of a pattern mask between the nonword prime and the word target, this visual activity, which might ordinarily obscure pseudohomophonic phonological priming, is markedly reduced or eliminated (Lukatela \& Turvey, 1994b).

The present experiment was directed at phonological priming by pseudohomophones, using a prime-target SOA of $250 \mathrm{msec}$. As in Experiment 1, prime processing in Experiment 2 was restricted to $125 \mathrm{msec}$ by a patterned mask inserted between the prime and the target. Lukatela and Turvey's (1994b) Experiment 5, with an SOA $=250 \mathrm{msec}$, had found reliable priming by homophonic nonwords without an intervening pattern mask. The use of an intervening mask in the present experiment provides both an opportunity to generalize the previous finding and a basis for comparison with investigations of phonological priming at considerably smaller SOAs in which an intervening mask has proven beneficial to demonstrating the effect.

\section{Method}

Participants. Forty-eight University of Connecticut undergraduates served as participants. A participant was assigned to one of eight groups, according to his or her time of appearance at the laboratory, to give a total of 6 participants per group. 
Table 3

\begin{tabular}{|c|c|c|c|c|c|c|c|c|}
\hline & \multicolumn{8}{|c|}{$\begin{array}{l}\text { Mean Naming Latencies (in Milliseconds) With } \\
\text { the Corresponding Standard Deviations by } \\
\text { Participants and by Items in Experiment } 2\end{array}$} \\
\hline & \multicolumn{2}{|c|}{ Identity } & \multicolumn{2}{|c|}{ Pseudohomograph } & \multicolumn{2}{|c|}{ Pseudohomophone } & \multicolumn{2}{|c|}{$\begin{array}{l}\text { Dedicated } \\
\text { Nonword }\end{array}$} \\
\hline & Test & Control & Test & Control & Test & Control & Test & Control \\
\hline \multicolumn{9}{|c|}{ One-Letter-Different Primes } \\
\hline$M$ & 505 & 544 & 535 & 553 & 513 & 551 & 554 & 550 \\
\hline$S D_{1}$ & 65 & 62 & 62 & 61 & 58 & 70 & 64 & 68 \\
\hline$S D_{2}$ & 45 & 41 & 36 & 41 & 34 & 39 & 42 & 39 \\
\hline \multicolumn{9}{|c|}{ Two-Letters-Different Primes } \\
\hline$M$ & 504 & 541 & 547 & 544 & 527 & 546 & 555 & 552 \\
\hline$S D_{1}$ & 73 & 60 & 68 & 62 & 69 & 59 & 64 & 63 \\
\hline$S D_{2}$ & 45 & 37 & 45 & 35 & 51 & 39 & 45 & 44 \\
\hline
\end{tabular}

Note $-S D_{1}$, standard deviation by participants; $S D_{2}$, standard deviation by items.

\begin{abstract}
Materials. The stimuli were identical to those in Experiment 1, except for the target words, which were made identical, within each line of stimuli shown in Appendices A and B, to the appropriate prime. With identity priming replacing appropriate associate priming, the designation prime frequency in the description above of stimulus materials should be changed to prime/target frequency.

Design and Procedure. These were identical to those in Experiment 1 .
\end{abstract}

\section{Results}

Table 3 presents the mean latencies and their $S D$ s for the major stimulus set of Appendix A. Table 2 presents the corresponding summary for the subsidiary stimulus set of Appendix B. An analysis of the test primes was done with respect to their individual controls and with respect to each other.

Analysis based on comparisons of test primes with individual controls. A $4 \times 2 \times 2 \times 2$ (prime type $\times$ relatedness $\times$ prime/target frequency $\times$ letter difference) omnibus ANOVA was conducted. With the exception of prime/target frequency, the factors were quasi-variables, as defined in Experiment 1. Both prime type $\left[F_{1}(3,141)=\right.$ $\left.42.48, p<.001 ; F_{2}(3,276)=22.90, p<.001\right]$ and relatedness $\left[F_{1}(1,47)=41.72, p<.001 ; F_{2}(1,92)=57.90\right.$, $p<.001]$ were reliable, as was the interaction between them $\left[F_{1}(3,141)=31.86, p<.001 ; F_{2}(3,276)=22.17, p<\right.$ $.001]$. Relatedness $\times$ letter difference was also reliable $\left[F_{1}(1,47)=5.22, p<.05 ; F_{2}(1,92)=4.66, p<.05\right]$. No other main effects or interactions reached significance.

Planned comparisons revealed that the 38-msec difference between identity primes and their individual controls was reliable $\left[F_{1}(1,47)=88.95, p<.001 ; F_{2}(1,92)=\right.$ $78.27, p<.001]$. Similarly, the 28 -msec difference between pseudohomophones and their individual controls was reliable $\left[F_{1}(1,47)=68.09, p<.001 ; F_{2}(1,92)=\right.$ $60.69, p<.001]$. The 7 -msec difference between pseudohomographs and their individual controls was not reliable $\left[F_{1}(1,47)=3.20, p>.05 ; F_{2}(1,92)=3.09, p>.05\right]$. Similarly unreliable was the 3 -msec difference between the dedicated nonwords and their individual controls (both $F \mathrm{~s}<1$ ). Of the partial interactions, those involving identity primes and pseudohomographs $\left[F_{1}(1,47)=32.55\right.$, $\left.p<.001 ; F_{2}(1,92)=30.36, p<.001\right]$, pseudohomophones and pseudohomographs $\left[F_{1}(1,47)=22.29, p<.001\right.$; $\left.F_{2}(1,92)=15.73, p<.001\right]$, and pseudohomophones and dedicated nonwords $\left[F_{1}(1,47)=46.23, p<.001\right.$; $\left.F_{2}(1,92)=30.95, p<.001\right]$ were reliable.

Important planned comparisons are those dealing with the one-letter and two-letters differences. First, for both pseudohomophones and pseudohomographs, differences with respect to the individual controls were less for the two-letters-different primes than for the one-letterdifferent primes $\left[F_{1}(1,47)=15.91, p<.001 ; F_{2}(1,92)=\right.$ $11.89, p<.001]$. Second, with respect to the differences between pseudohomophones and their controls, priming was stronger for one-letter-different (e.g., ROZE) than for two-letters-different (e.g., RANE) pseudohomophones [38 vs. $19 \mathrm{msec} ; F_{1}(1,47)=7.38, p<.01 ; F_{2}(1,92)=7.15$, $p<.01]$. A very similar pattern was seen with respect to just the pseudohomographs: one-letter-different primes (e.g., ROYE) were distinguished from their controls more than two-letters-different primes (e.g., RANS) were distinguished from their controls [ $18 \mathrm{vs} .-3 \mathrm{msec} ; F_{1}(1,47)=$ $\left.11.01, p<.01 ; F_{2}(1,92)=5.51, p<.05\right]$. There is a further important fact having to do with the relative sizes of the differences between pseudohomophones and their controls and between pseudohomographs and their controlsnamely, the comparison for two-letters-different primes was as reliable as the comparison for one-letter-different primes. The RANE versus NAIM difference, as compared with the RANS versus NALM difference, yielded $F_{1}(1,47)=$ $15.41, p<.001, F_{2}(1,92)=9.25, p<.01$, and the ROZE versus DEEL difference, as compared with the ROYE versus DERL difference, yielded $F_{1}(1,47)=8.69, p<.01$, $F_{2}(1,92)=6.86, p<.01$.

Analysis based on comparisons among test primes. A $4 \times 2 \times 2$ (prime type $\times$ prime/target frequency $\times$ letter difference) ANOVA revealed an effect of prime type $\left[F_{1}(3,141)=67.97, p<.001 ; F_{2}(3,276)=41.84, p<\right.$ $.001]$. No other main effect and none of the interactions was reliable.

Planned comparisons were conducted. The $50-\mathrm{msec}$ difference between the identity primes and the dedicated 
nonword primes was reliable $\left[F_{1}(1,47)=113.78, p<.001\right.$; $\left.F_{2}(1,92)=101.15, p<.001\right]$, as were the 35 -msec difference between pseudohomophone primes and the dedicated nonword primes $\left[F_{1}(1,47)=135.15, p<.001 ; F_{2}(1,92)=\right.$ $56.91, p<.001]$ and the $13-\mathrm{msec}$ difference between the pseudohomographic primes and the dedicated nonword primes $\left[F_{1}(1,47)=17.10, p<.001 ; F_{2}(1,92)=7.20, p<\right.$ $.01]$. Identity primes were superior to pseudohomophone primes $\left[F_{1}(1,47)=8.86, p<.001 ; F_{2}(1,92)=9.15, p<\right.$ $.01]$ and pseudohomograph primes $\left[F_{1}(1,47)=59.29\right.$, $\left.p<.001 ; F_{2}(1,92)=66.93, p<.001\right]$. Importantly, the 22 -msec difference favoring pseudohomophone primes over pseudohomographic primes was reliable $\left[F_{1}(1,47)=\right.$ $\left.42.11, p<.001 ; F_{2}(1,92)=23.04, p<.001\right]$. The preceding overall advantage was upheld by both one-letterdifferent pseudohomophones [a 23-msec advantage over one-letter-different pseudohomographs; $F_{1}(1,47)=18.60$, $\left.p<.001 ; F_{2}(1,92)=15.70, p<.001\right]$ and two-lettersdifferent pseudohomophones [a 20-msec advantage over two-letters-different pseudohomographs; $F_{1}(1,47)=$ $\left.17.58, p<.001 ; F_{2}(1,92)=8.39, p<.01\right]$. It is noteworthy that (1) two-letters-different pseudohomographs were not different from the dedicated nonwords $\left[F_{1}(1,47)=\right.$ $\left.2.61, p>.05 ; F_{2}(1,46)=1.68, p>.05\right]$, but $(2)$ twoletters-different pseudohomophones were different from the dedicated nonwords $\left[F_{1}(1,47)=46.40, p<.001\right.$; $\left.F_{2}(1,46)=15.24, p<.001\right]$.

In the analyses based on comparisons between test primes and their individualized controls, a reliable difference was found favoring one-letter-different primes (pseudohomophones and pseudohomographs) over twoletters-different primes (pseudohomophones and pseudohomographs). In the present analysis based on comparisons among test primes, there was no such reliable difference favoring one-letter-different primes (all $p s>.05$ ).

Analysis of CODE-like stimuli. Prime type (essentially the eight lists of primes within the design: CODE, KODE, KODE, COAD, COAD, KOAD, HODE, and FISH) was reliable $\left[F_{1}(7,329)=19.67, p<.001\right]$. Planned comparisons revealed highly reliable differences on the order of $61 \mathrm{msec}$ between CODE and HODE $\left[F_{1}(1,329)=98.34, p<.001\right]$, $35 \mathrm{msec}$ between KODE and HODE $\left[F_{1}(1,329)=22.88, p<\right.$ $.001], 34 \mathrm{msec}$ between COAD and HODE $\left[F_{1}(1,329)=\right.$ $31.00, p<.001]$, and $31 \mathrm{msec}$ between KOAD and HODE $\left[F_{1}(1,329)=25.91, p<.001\right]$. In contrast, the 6-msec difference that favored FISH over HODE was not significant $\left[F_{1}(1,329)<1\right]$. The 55 -msec difference that favored the identity priming (CODE) over control word priming (FISH) and that represents the net magnitude of identity priming was highly significant $\left[F_{1}(1,329)=80.07, p<.001\right]$. Generally, identity priming was significantly greater than priming by any other prime type. Of special note, the 25-msec difference that favored KOAD over the control FISH and that represents the magnitude of phonologic facilitation produced by a three-letters-different pseudohomophone was also significant $\left[F_{1}(1,329)=16.98, p<.001\right]$.
Similarly, all other pseudohomophone primes produced a significant phonologic facilitation with regard to FISH $(p>.05)$.

\section{Discussion}

The results of Experiment 2 confirm and extend recent observations of pseudohomophonic priming (Lukatela \& Turvey, 1994b). In the major stimulus set and in both analyses (with and without individual controls), priming occurred for both one-letter different and two-lettersdifferent pseudohomophones and to a greater degree than did priming by the corresponding pseudohomographs. In the subsidiary stimulus set (CODE-like stimuli), priming occurred equivalently for one-letter-, two-letters-, and three-letters-different nonword homophonic primes, in comparison with no priming by one-letter-different nonword nonhomophonic primes. For the analysis of the major stimuli using the individual controls, pseudohomophones were not statistically different from identity primes, as had previously been shown by Lukatela and Turvey (1994b, Expcriment 5) for the same SOA of approximately $250 \mathrm{msec}$ but within a three-field presentation that lacked a mask inserted between prime and target. As was noted in the introduction, previous failures to find pseudohomophonic priming at short time scales were used to make the case, from a dual-route perspective, that assembled (nonlexical) phonology was perhaps strategic rather than automatic, slow relative to addressed phonology, and possibly nonexistent (Humphreys et al., 1982).

As was noted in the introduction, it is expected, on the basis of the phonological coherence hypothesis, that, with prolonged SOAs, orthographic factors will become more influential. In particular, the evolving visual-semantic resonance, functioning as a kind of implicit spelling check, should result in different priming effects of words and pseudohomophones and, furthermore, different priming effects of one-letter-different pseudohomophones and two-letters-different pseudohomophones. By the same intuitive argument, when two letters are different, the pseudoword is computed to be a nonword sooner than when one letter is different. Evidence for the influence of visual-semantic resonance might have been provided by the analysis involving individual controls, which revealed that pseudohomophones that differed by two letters from their targets were less effective than those that differed by only one letter. It will be recalled that, in Experiment 1, two-letters-different pseudohomophones were not significantly better primes than their two-lettersdifferent pseudohomograph mates. There is reason to argue, however, that the present result may not have been a true effect of letter differences on the contribution of phonology. This argument is suggested by the findings that (1) within the same analysis, pseudohomographs showed an identical advantage for one-letter-different primes and (2) within the analysis restricted to test primes, pseudohomophones with two letters different were 
Table 4

Mean Naming Latencies (in Milliseconds)

With the Corresponding Standard Deviations

by Participants and by Items in Experiment 3

\begin{tabular}{|c|c|c|c|c|c|c|c|c|}
\hline & \multicolumn{2}{|c|}{ Identity } & \multicolumn{2}{|c|}{ Pseudohomograph } & \multicolumn{2}{|c|}{ Pseudohomophone } & \multicolumn{2}{|c|}{$\begin{array}{l}\text { Dedicated } \\
\text { Nonword }\end{array}$} \\
\hline & Test & Control & Test & Control & Test & Control & Test & Control \\
\hline \multicolumn{9}{|c|}{ One-Letter-Different Primes } \\
\hline$M$ & 511 & 541 & 531 & 539 & 524 & 540 & 541 & 541 \\
\hline$S D_{1}$ & 72 & 57 & 68 & 61 & 58 & 60 & 62 & 62 \\
\hline$S D_{2}$ & 38 & 33 & 42 & 39 & 30 & 37 & 38 & 39 \\
\hline \multicolumn{9}{|c|}{ Two-Letters-Different Primes } \\
\hline$M$ & 511 & 538 & 531 & 539 & 522 & 542 & 536 & 540 \\
\hline$S D_{1}$ & 62 & 70 & 67 & 62 & 70 & 63 & 57 & 61 \\
\hline$S D_{2}$ & 39 & 44 & 39 & 44 & 50 & 42 & 41 & 43 \\
\hline
\end{tabular}

equally as effective as pseudohomophones with one letter different.

Although the principle focus of Experiment 2 was phonological priming, the results bear, in addition, on orthographic priming. Primes such as ROYE were significantly better than their individualized controls (by $18 \mathrm{msec}$ ), and within the analysis restricted to test stimuli, it was the case that, collectively, primes such as ROYE and RANS were significantly better (by $13 \mathrm{msec}$ ) than the common control. This evidence for orthographic priming at the long prime-target SOA of $250 \mathrm{msec}$ would seem to be contradictory to the view that such priming arises from short-lived persistence of activity in the input layer of visual features and is, therefore, limited to very brief temporal lags between prime and target (e.g., Lukatela \& Turvey, 1994b). Perhaps, the proper tack to take on this evidence for orthographic priming is phonological; that is, the priming of rose by ROYE might be more appropriately interpreted as arising from partially shared phonology, rather than from a common subset of letters. This tack would be consistent with the phonological coherence hypothesis and the implied primacy of phonological coding.

Of relevance to the latter is the argument that rhyme priming at very short prime-target SOAs ought to be inhibitory rather than facilitatory, because a rhyme (e.g., HOSE for rose) creates an initially competitive phonological code that must be overcome within the visualphonological network during the processing of the target (i.e., rose). Experiments support this expectation of inhibitory rhyme priming at short SOAs (Lukatela \& Turvey, 1996). In order to accommodate the facilitatory effects of primes such as ROYE for the target rose in the present experiment with an SOA of $250 \mathrm{msec}$, one would have to assume that, at long lags between prime and target, the processing benefits of the phonological subpatterns that are shared between them outweigh the processing costs of the phonological subpatterns that are not shared.

\section{EXPERIMENT 3}

Experiment 3 replicated the conditions of Experiment 2 with a much reduced average prime-target SOA of $34 \mathrm{msec}$ (and an average prime duration of $21 \mathrm{msec}$ ). At issue was whether the results found in Experiment 2 would be reproduced and, in particular, whether the apparent contrast between one-letter-different primes and two-letters-different primes in the analysis involving individual controls would be maintained. Previous research with the mask-prime-mask-target presentation sequence has demonstrated an effect of nonwords on the naming of homophonic word targets at average primetarget SOAs $\leq 50 \mathrm{msec}$ (Lukatela \& Turvey, 1994b). This effect at very short SOAs may depend crucially on the conditions of presentation. Using a mask-prime-target presentation, Grainger and Ferrand (1996) failed to observe phonological priming by pseudohomophones in the naming task at $S O A \approx 40 \mathrm{msec}$.

\section{Method}

Participants. Seventy-two University of Connecticut undergraduates served as participants. A participant was assigned to one of eight groups, according to his or her time of appearance at the laboratory, to give a total of 9 participants per group.

Materials and Design. These were identical to those in Experiment 2.

Procedure. This differed from Experiment 2 only in the timing of the stimuli: a shorter average exposure $(21 \mathrm{msec})$ of the prime and a shorter average exposure $(13 \mathrm{msec})$ of the interpolated mask, to yield an average prime-target SOA of $34 \mathrm{msec}$.

\section{Results}

Table 4 presents the mean latencies and their $S D$ s for the major stimulus set of Appendix A. Table 2 presents the corresponding summary for the subsidiary stimulus set of Appendix B. An analysis of the test primes was done with respect to their individual controls and with respect to each other. 
Analysis based on comparisons of test primes with individual controls. A preliminary analysis revealed that the prime/target frequency was not a significant factor (all $F$ s involving the prime/target frequency were less than 1 ). Therefore, a $4 \times 2 \times 2$ (prime type $\times$ relatedness $\times$ letter difference) omnibus ANOVA was conducted. The factors were quasi-variables, as defined in Experiment 1. Prime type $\left[F_{1}(3,213)=20.32, p<.001 ; F_{2}(3,282)=\right.$ $10.81, p<.001]$, relatedness $\left[F_{1}(1,71)=89.43, p<.001\right.$; $\left.F_{2}(1,94)=42.45, p<.001\right]$, and the two-way interaction between prime type and relatedness $\left[F_{1}(3,213)=17.96\right.$, $\left.p<.001 ; F_{2}(3,282)=5.00, p<.01\right]$ were reliable. No other main effects or interactions reached significance.

Planned comparisons revealed a reliable 28 -msec difference between identity primes and their individualized controls $\left[F_{1}(1,71)=101.84, p<.001 ; F_{2}(1,94)=30.40\right.$, $p<.001]$ and a reliable 18 -msec difference between pseudohomophone primes and their individualized controls $\left[F_{1}(1,71)=53.08, p<.001 ; F_{2}(1,94)=12.47, p<\right.$ $.001]$. Neither the 8 -msec difference between pseudohomographic primes and their individualized controls $\left[F_{1}(1,71)=6.69, p<.01 ; F_{2}(1,94)<1\right]$ nor the 2 -msec difference between the dedicated nonwords and their individualized controls $(F \mathrm{~s}<1)$ was reliable. Priming by pseudohomophones differing by one letter from their targets was a reliable $17 \mathrm{msec}$ faster than priming by their individualized controls $\left[F_{1}(1,71)=17.98, p<.001\right.$; $\left.F_{2}(1,47)=7.29, p<.01\right]$. Similarly, priming by pseudohomophones differing by two letters from their targets was a reliable $20 \mathrm{msec}$ faster than priming by their individualized controls $\left[F_{1}(1,71)=29.60, p<.001 ; F_{2}(1,47)=\right.$ $5.82, p<.05]$. Neither one-letter-different pseudohomographs $\left[F_{1}(1,71)=3.28, p>.05 ; F_{2}(1,47)<1\right]$ nor twoletters-different pseudohomographs $\left[F_{1}(1,71)=4.66, p<\right.$ $\left..05 ; F_{2}(1,47)<1\right]$ proved to be reliable primes (effects of $8 \mathrm{msec}$ in both cases).

With respect to partial interactions, pseudohomophonic priming was not reliably smaller than identity priming $\left[F_{1}(1,71)=7.17, p<.01 ; F_{2}(1,94)=2.03, p>.05\right]$ and not reliably larger than pseudohomographic priming $\left[F_{1}(1,71)=10.11, p<.01 ; F_{2}(1,94)=1.62, p>.05\right]$; it was reliably larger, however, than the priming by dedicated nonwords $\left[F_{1}(1,71)=20.60, p<.001 ; F_{2}(1,94)=4.43\right.$, $p<.05]$. Pseudohomographic primes and dedicated nonword primes were not reliably different $(F \mathrm{~s}<1)$.

Analysis based on comparisons among test primes. A $4 \times 2 \times 2$ (prime type $\times$ prime frequency $\times$ letter difference) ANOVA revealed an effect of prime type $\left[F_{1}(3,213)=33.03, p<.001 ; F_{2}(3,282)=11.93, p<\right.$ $.001]$. No other main effect and none of the interactions was reliable.

In the planned comparisons, the $27-\mathrm{msec}$ difference between identity primes and dedicated nonword primes and the 16-msec difference between pseudohomophone primes and dedicated nonword primes were both reliable $\left[F_{1}(1,71)=80.43, p<.001, F_{2}(1,94)=42.37, p<.001\right.$, and $F_{1}(1,71)=31.37, p<.001, F_{2}(1,94)=9.10, p<.01$, respectively]. In contrast, the 7 -msec difference between pseudohomographs and dedicated nonwords was not reliable $\left[F_{1}(1,71)=4.68, p<.05 ; F_{2}(1,94)=2.97, p>\right.$ $.05]$. With respect to the comparisons among the theoretically relevant primes, identity primes were superior to both pseudohomophones (11-msec advantage) and pseudohomographs [20-msec advantage; $F_{1}(1,71)=$ $19.18, p<.001, F_{2}(1,94)=8.48, p<.01$, and $F_{1}(1,71)=$ $53.96, p<.001, F_{2}(1,94)=14.01, p<.001$, respectively]. The 9-msec difference favoring pseudohomophones over pseudohomographs was significant by participants $\left[F_{1}(1,71)=9.53, p<.01\right]$, but not by items $\left[F_{2}(1,94)=\right.$ $2.28, p>.05]$. There was no difference $\left(F_{\mathrm{S}}<1\right)$ between one-letter-different primes (pseudohomophones and pseudohomographs) and two-letters-different primes (pseudohomophones and pseudohomographs).

Analysis of CODE-like stimuli. Prime type (essentially the eight lists of primes within the design: CODE, KODE, KODE, COAD, COAD, KOAD, HODE, and FISH) was reliable $\left[F_{1}(7,497)=8.99, p<.001\right]$. Planned comparisons revealed highly reliable differences on the order of $33 \mathrm{msec}$ between CODE and HODE $\left[F_{1}(1,497)=41.36, p<.001\right]$, $18 \mathrm{msec}$ between KODE and HODE $\left[F_{1}(1,497)=11.78\right.$, $p<.001], 24 \mathrm{msec}$ between COAD and HODE $\left[F_{1}(1,497)=\right.$ $21.91, p<.001]$, and $18 \mathrm{msec}$ between KOAD and HODE $\left[F_{1}(1,497)=12.69, p<.001\right]$. In contrast, the 8-msec difference that favored FISH over HODE was not significant $\left[F_{1}(1,497)=2.46, p>.05\right]$. The $25-\mathrm{msec}$ difference that favored the identity priming (CODE) over control word priming (FISH) and that represents the net magnitude of identity priming was highly significant $\left[F_{1}(1,497)=23.65\right.$, $p<.001]$. Generally, in the present experiment, the identity priming was significantly faster than the priming by any other prime type. Of special note, the 10-msec difference that favored KOAD over the control FISH, which represents the magnitude of phonologic facilitation produced by a three-letters-different pseudohomophone, was also significant $\left[F_{1}(1,497)=3.98, p<.05\right]$.

\section{Discussion}

Under the mask-prime-mask-target conditions of the present experiment, with an average prime-target SOA of $34 \mathrm{msec}$, pseudohomophones in the major and subsidiary stimulus sets proved to be significant primes. In the major set, their priming was significant relative to both individual control primes and a common control prime, but not relative to the pseudohomographs. In the subsidiary set, the priming by all of the CODE-like pseudohomophones was better than that by the graphemically similar, rhyming prime. Relative to neither type of control and in neither stimulus set was there evidence of reliable priming by pseudohomographs.

The level of priming was much less in Experiment 3, with its much shorter prime exposure and prime-target SOA, than in Experiment 2, in agreement with earlier observations on identity priming by Warren (1977). Despite this magnitude difference, the patterns of results in the two experiments were closely similar. One contrast was that the priming superiority of pseudohomophones over 
pseudohomographs in the major stimulus set was more pronounced within the analyses of Experiment 3 when based on the comparisons of test primes with their individualized controls than when based on the comparisons among test primes. This contrast might be suggestive of the larger importance of individualized controls in revealing priming effects at very brief time scales (Lukatela \& Turvey, 1994a, 1994b). A potentially important aspect of Experiment 2 that was not replicated in Experiment 3 was the advantage within the major stimulus set of oneletter-different pseudohomophones and pseudohomographs when evaluated through individualized controls. In Experiment 3 and in both analyses (with and without individualized controls), one-letter-different and twoletters-different pseudohomophones primed identically, and there was no priming by either one-letter- or twoletters-different pseudohomographs. This latter pattern of results was buttressed by the outcome of the analysis of the subsidiary stimulus set: one-letter-, two-letters-, and three-letters-different homophonic nonwords primed reliably and similarly, but one-letter-different nonhomophonic nonwords did not prime.

The preceding outcome for the subsidiary stimuli should be compared with the onset effect reported by Forster and Davis (1991). In a naming task with masked primes, they found that pairs such as take-BREAK did not differ from their control pairs (merry-BREAK) but that pairs with identical onsets, such as belly-BREAK, did differ from the controls in the direction of faster naming of the target. Forster and Davis conjectured that a Stroop-like interference effect was produced in take-BREAK pairs by competing tendencies to pronounce both the prime and the target. By the same token, a common initial pronunciation, as in belly-BREAK, produces Stroop-like facilitation. It would seem, therefore, that in the masked priming of naming, onset identity is more important than overall phonological similarity. Accordingly, the results for the subsidiary stimuli of Experiments 2 and 3 could be interpreted as manifestations of this Stroop-like interference arising from onset differences, rather than from phonological similarity (consider COAD-coat and KOAD-coat vs. HODE-coat). Against such an interpretation, however, are the results for the major stimulus set: Pseudohomophones and pseudohomographs were alike in sharing their initial phoneme(s) with their targets, but only the pseudohomophones were effective primes. A general onset argument can also be rejected by a consideration of the results of other, similar experiments. Lukatela and Turvey (1994b) found that, whereas toad was named faster following TOWED than following PLASM (the matched control for TOWED), the naming of toad following TOLD was no faster than the naming of toad following GAVE (the matched control for TOLD). Similarly, priming of toad by the nonword TODE (relative to the control LAIM-toad) was more reliable than priming of toad by the nonword TODS (relative to the control LARM-toad) at brief SOAs. If onset identity, and not phonological similarity, mattered, TOLD and ToDs (same onsets as toad) should have been as dif- ferent from GAVE and LARM (different onsets than toad), respectively, as TOWED and TODE were different from PLASM and LAIM, respectively.

An important aspect of Experiments 2 and 3, evident in both major and subsidiary sets of stimuli, is that the observed priming was very dependent on homophony. When primes looked like their targets but did not sound like them, priming was significantly reduced (Experiment 2) or absent altogether (Experiment 3 ). It has often been suggested that orthographic priming depends on conditions of masking, occurring only when primes are unidentifiable (e.g., Davis \& Forster, 1994). In respect to this suggestion, it is perhaps important to note that, although primes were more likely to be identified in Experiment 2 than in Experiment 3, pseudohomographs primed more successfully in Experiment 2 than in Experiment 3 . It is also of value to note that the phonological interpretation of the pseudohomograph priming under the prolonged SOA of Experiment 2 receives some support from the absence of pseudohomographic priming in Experiment 3 . When the prime-target SOA is much reduced (from the $250 \mathrm{msec}$ of Experiment 2 to the $34 \mathrm{msec}$ of Experiment 3), it can be argued that the potential benefits of the incompletely shared phonology of, say, ROYE and rose do not have sufficient time to materialize.

\section{EXPERIMENT 4}

Although the overall pattern of results of Experiment 3 was favorable to the phonological coherence hypothesis, two major nonsignificant outcomes in the main stimulus set weaken the evidence. These were (1) the lack of interaction between pseudohomophones and their individualized controls, on the one hand, and between pseudohomographs and their individualized controls, on the other hand, and (2) the lack of a significant difference between pseudohomophones and pseudohomographs in the analyses restricted to test primes. These nonsignificant outcomes are important because they reflect most directly upon the effect of phonological similarity over and above that of orthographic similarity (or, alternatively, the effect of fully vs. partially shared phonology). Thus, although Experiment 3 yielded evidence for effective priming by pseudohomophones, relative to individualized nonword control primes, it did not find evidence for effective priming by pseudohomophones, relative to their visually similar controls.

In part, the absence of clear effects was due to the small differences among conditions that are typically the case when the naming task is combined with the four-field presentation sequence (Lukatela \& Turvey, 1994b). The intervening (postprime, pretarget) mask designed to reduce purely figural influences of the prime on the target seems also to reduce the degree of phonological priming. In Experiment 4, the postprime mask was eliminated, and relevant manipulations were made in the context of a mask-prime-target procedure- that is, without the intervening mask. The absence of clear effects was also 
due, in part, to the lack of power in the design of Experiment 3 , resulting from very few stimuli per condition. In Experiment 4, the number of experimental conditions was reduced to 6 (from 16), with the number of stimuli per condition increased to 24 (from 6). The reduction in conditions followed from focusing on the primary contrast of a pseudohomophone (e.g., KLIP, HEET, or NAIM) with its pseudohomographic control (PLIP, HERT, and NART, respectively). This particular contrast is the best available measure of the contribution of phonology over and above the contribution of orthography (Lukatela, Frost, \& Turvey, 1998).

\section{Method}

Participants. Twenty University of Connecticut undergraduates participated in the experiment in partial fulfillment of a course requirement. Each participant was randomly assigned to one of two groups (10 participants per group).

Materials. Three base sets (the $\mathrm{C}$-set, the $\mathrm{H}$-set, and the $\mathrm{N}$-set), each of 48 word--word pairs, were assembled (see Appendices C, D, and E). As in Experiments 2 and 3, the prime and the target were two identical words, with the prime in uppercase and the target in lowercase. Each word was a monosyllable consisting of four or five letters (e.g., CLIP-clip in the C-set, HEAT-heat in the H-set, and NAME-name in the N-set). An objective of Experiment 4 was to separate, as far as possible, the phonological priming effects from extraneous and possibly confounding priming effects tied to the visual form of the masked prime. To this purpose, short, monosyllabic words were chosen, because usually they have high neighborhood densities-a feature typically assumed to be detrimental to masked form priming (Forster, 1987; Forster \& Davis, 1991). There was, in addition, a subset of foils. These latter prime-target pairs were highly diversified in order to further minimize the development of any specific response strategies.

All the words in the C-set were chosen to be C-initial words, because such words, as was noted above, provide the most copious examples of English words with pseudohomophones that are created by a change in the first letter. In the terminology of Berent and Perfetti (1995), most of the word bodies of the C-set contained simple one-letter vowel graphemes. According to Kučera and Francis (1967), the mean frequency of the target words in this base set was $44.17 \pm 71.40$. The mean letter length was 4.42 .

One test set and one control set of 48 pairs were generated from the base $\mathrm{C}$-set. In the test $\mathrm{C}$-set, the initial letter $\mathrm{C}$ in the prime was replaced by the letter $\mathrm{K}$ (e.g., KLIP-clip, KLERK-clerk), producing 48 phonologically matched test pairs. In the control $C$-set, the initial letter $C$ in the prime was replaced by a letter representing a consonant other than $/ \mathrm{k} /$ (e.g., PLIP-clip, PLERK-clerk), producing 48 phonologically mismatched control pairs.

The words in the H-set were chosen so that special triplets of items could be created, such as HEAT, HEET, and HERT. According to Kučera and Francis (1967), the mean frequency of the target words in the $\mathrm{H}$-set was $45.21 \pm 79.30$. The mean letter length was 4.42 (the same as in the C-set). One test set and one control set of 48 pairs were generated from the base $\mathrm{H}$-set. In the test $\mathrm{H}$-set, one interior letter in each prime was replaced by another letter to preserve homophony (e.g., HEET-heat, STEEM-steam). The mean letter position at which the test prime and its target differed was $2.90 \pm 0.91$. In the control H-set, one letter was replaced by another letter to destroy homophony (e.g., HERT-heat, STEAP-steam). It should be noted that each control prime was homophonic with some other, unrelated word. The mean letter position at which the control prime and its target differed was $3.04 \pm 1.25$.
Words in the N-set were chosen to provide the creation of twoletters-different pseudohomophones and pseudohomographs (e.g., NAIM-NART-name). According to Kučera and Francis (1967), the mean frequency of the target words was $90.10 \pm 135.40$. The mean letter length was 4.27 . The prime and the target did not overlap in either their third or their fourth letter positions, in the case of fourletter-long words, or in their fourth and fifth letter positions, in the case of five-letter words. One test set and one control set of 48 pairs were generated from the base $\mathrm{N}$-set. In the test $\mathrm{N}$-set, two letters in each prime were replaced, preserving homophony (e.g., NAIMname, STOAN-stone). In the control N-set, two letters in each prime were replaced, violating homophony (e.g., NART-name, sTOOKstone).

Finally, 108 prime-target pairs as foils were assembled, in which each target was a word. The prime was an identity word, an associatively related word, an unrelated word, a homophonic nonword, a nonhomophonic nonword, or a row of Xs (the number of Xs matched the number of letters in the target). All the nonword primes, excluding the $\mathrm{X}$ primes, were orthographically legal and pronounceable nonwords.

Design. The major constraint of the design was that a given participant never encountered a given pair of words more than once. This was achieved by dividing the 20 participants into two subgroups. Each participant saw one half of the pairs from the test C-list (KLIPclip), the test H-list (HEET-heat), and the test N-list (NAIM-name), one half of the pairs from the control C-list (PLIP-clip), the control $\mathrm{H}$-list (HERT-heat), and the control N-list (NART-name), and 108 foil pairs. In sum, each participant saw a total of 252 stimulus pairs. The experimental sequence was divided into three subsets, with a brief rest after each. The experimental sequence was preceded by a practice sequence of 50 stimulus pairs.

Procedure. The participant sat in front of the monitor of a Digital 466 computer in a dimly lit room. The viewing distance was about $60 \mathrm{~cm}$. The refresh rate of the Venturix monitor was $70 \mathrm{~Hz}$, making a refresh cycle (i.e., a tick) equal to $14.3 \mathrm{msec}$. The stimuli appeared on the screen as white characters on a dark background. Each trial consisted of a sequence of three visual events in the same location on the center of the screen. First, a pattern mask consisting of a row of five hashmarks (\#\#\#\#) was presented for 35 ticks $(500 \mathrm{msec})$; this was immediately followed by the prime stimulus for 4 ticks ( $57 \mathrm{msec})$. Immediately following the prime, a target was presented for 15 ticks $(215 \mathrm{msec})$. Because the ISI was zero, the prime target SOA was $57 \mathrm{msec}$. (Presentation and control of stimuli were through the DMASTR software, developed at Monash University and University of Arizona by K. I. Forster and J. C. Forster.)

The participants were told that, on each trial, there would be a rapid sequence of two letter strings with the first letter string in uppercase and the second letter string in lowercase. They were warned that the first letter string would be flashed very briefly and would probably be unnoticable. The participants were instructed to read aloud, as quickly and as accurately as possible, the lowercase word, ignoring the uppercase letter string. The naming latencies were measured from the onset of the target. If the latency was longer than $1,400 \mathrm{msec}$, a warning message ("TRY FASTER!") appeared on the screen. Debriefing following the experiment revealed that almost all the participants failed to identify the primes.

\section{Results and Discussion}

Response latencies were trimmed minimally by applying a 100 -msec cutoff for fast responses and a 1,400 -msec cutoff for slow responses. The outliers constituted less than $0.2 \%$ of all the responses. The mean latencies and errors $(\%)$ for the test and control pairs in each of the three stimulus sets (C-, H-, and N-sets) were KLIP $(510 \mathrm{msec}$, 


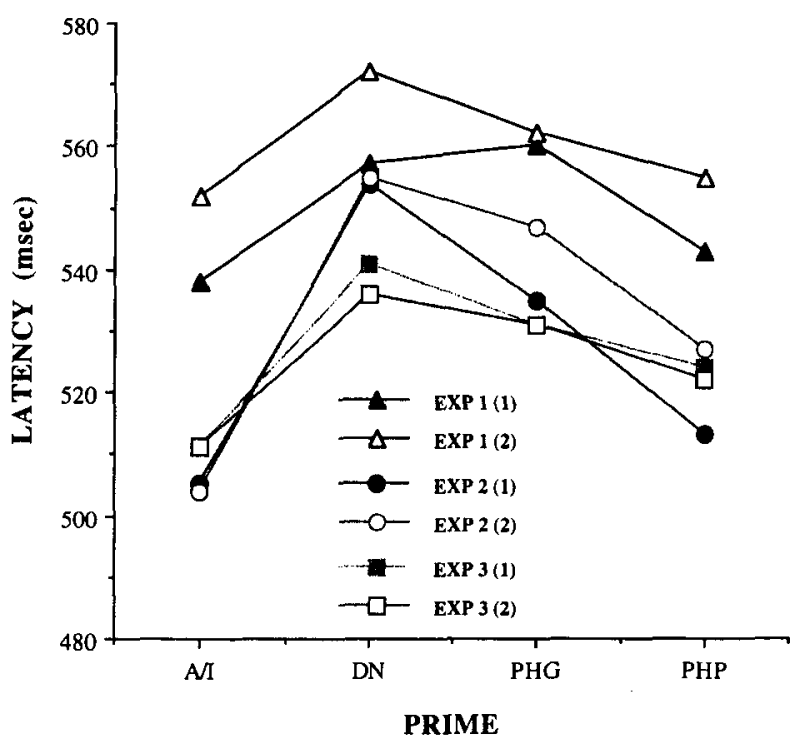

Figure 1. Target latencies following the test primes of the major stimulus set for each of Experiments 1-3. Parenthesized numbers identify the stimulus subsets for one-letter-different nonwords and two-letters-different nonwords. A/I, appropriate prime (Experiment 1) or identity prime (Experiments 2 and 3); DN, dedicated nonword; PHG, pseudohomograph; PHP, pseudohomophone.

$.42)$ versus PLIP ( $527 \mathrm{msec}, .21)$, HEET $(517 \mathrm{msec}, .84)$ versUs HERT ( $529 \mathrm{msec}, .63)$, NAIM ( $500 \mathrm{msec}, 0)$ versus NART (508 msec, .63).

A $2 \times 3 \times 2$ (group $\times$ set $\times$ prime type) ANOVA was conducted on the correct reaction times to word targets, with participants $\left(F_{1}\right)$ and stimuli or items $\left(F_{2}\right)$ as the error terms. Prime type (test $=509 \mathrm{msec}$, control $=521 \mathrm{msec}$ ) was significant $\left[F_{1}(1,18)=44.07, p<.001 ; F_{2}(1,46)=\right.$ $49.88, p<.001]$. The main effect of stimulus set was also significant $\left[F_{1}(2,36)=40.26, p<.001 ; F_{2}(2,92)=7.37\right.$, $p<.001]$. The two-way interaction between prime type and stimulus set did not reach significance $\left[F_{1}(2,36)=\right.$ $\left.2.04, p>.05 ; F_{2}(2.92)=1.65, p>.05\right]$. The three-way interaction was significant by participants, but not by items $\left[F_{1}(2,36)=20.37, p<.001 ; F_{2}(2,92)=1.84, p>.05\right]$. (There were no significant effects in the error analysis.)

Planned comparisons (i.e., the pseudohomophone tests) revealed that the $17-\mathrm{msec}$ phonological priming advantage of KLIP-clip over PLIP-clip was significant $\left[F_{1}(1,18)=\right.$ $\left.22.44, p<.001 ; F_{2}(1,46)=19.73, p<.001\right]$. Similarly, the 12-msec phonological priming advantage of HEET-heat over HERT-heat was significant $\left[F_{1}(1,18)=28.38, p<\right.$ $\left..001 ; F_{2}(1,46)=14.38, p<.001\right]$. The 8-msec phonological priming advantage of NAIM-name over NART-name was also significant $\left[F_{1}(1,18)=5.92, p<.05 ; F_{2}(1,46)=\right.$ 7.98, $p<.01]$.

Of additional interest are the partial interactions. KLIP versus PLIP $(17 \mathrm{msec})$ was not reliably larger than HEET versus HERT $\left[12 \mathrm{msec} ; F_{1}(1,18)=1.31, p>.05 ; F_{2}(1,46)<\right.$ 1]. Importantly, neither KLIP versus PLIP ( $17 \mathrm{msec})$ nor HEET versus HERT ( $12 \mathrm{msec}$ ) was reliably larger than NAIM versus NART $\left[8 \mathrm{msec} ; F_{1}(1,18)=2.73, p>.05 ; F_{2}(1,46)=3.35\right.$, $p=.07$, and $F_{1}(1,18)=1.41, p>.05 ; F_{2}(1,46)<1$, respectively].

The results indicate that both the one-letter-different and the two-letters-different pseudohomophone primes passed the pseudohomophone test. The ability of a pseudohomophone to function as a successful phonological prime does not seem to be critically constrained by the number of letters (one or two) by which the pseudohomophone differs from the target. In the above ANOVA, no interaction involving stimulus set reached significance. Nonetheless, there were numerical differences among the mean naming latencies $(17,14$, and $8 \mathrm{msec}$, for the primes with one different initial letter, one different middle letter, and two different middle letters, respectively), suggesting that the number of shared letters plays a role, albeit nondecisive, in phonological priming. Indeed, in the ANOVA's item analysis, the priming advantage of KLIPclip over PLIP-clip $(17 \mathrm{msec})$ was marginally stronger than the priming advantage of NAIM-name over NARTname $(8 \mathrm{msec})$. As was noted in the introduction, there is, perhaps, an orthographic contribution at very brief time scales that can be traced to the visual-phonological resonance. This resonance may well be sensitive to the whole word's orthographic form - that is, the canonical (normal, typical) form in which the word's phonology is conveyed.

Another lesson of Experiment 4 is that the position of the nonshared letter in one-letter-different primes may be of minimal importance. KLIP and HEET primed equally. The latter observation is of additional relevance, because it implies that the onset effect that is potentially present in Experiment 4 did not prevail over other design factors.

\section{GENERAL DISCUSSION}

The four experiments in the present study were directed primarily at the question of whether the number of letter differences between a nonword and a word of identical phonology affects the nonword's ability to function like the word in associative and phonological priming. In answer, the results show that a pseudohomophone's priming ability is relatively insensitive to how it is spelled.

In Experiment 1, nonwords in the major stimulus set differed from their phonologically identical word partners either by one letter (with three or four letters shared) or by two or three letters (with two letters shared). The results showed that, for the majority of the analyses, these different nonword primes were equivalent in their ability to prime an associate of the word and were statistically indistinguishable in this regard from the word itself. Thus, ROZE primed flower as effectively as RANE primed wet, and ROZE and RANE primed as well as ROSE and RAIN, respectively. In comparison, ROZE and RANE's orthographic nonword partners, ROYE and RANS, failed to prime. Orthographic similarity in the absence of phonological identity is an insufficient basis for pseudoassociative priming (Lukatela \& Turvey, 1994a). Complementary evidence is 


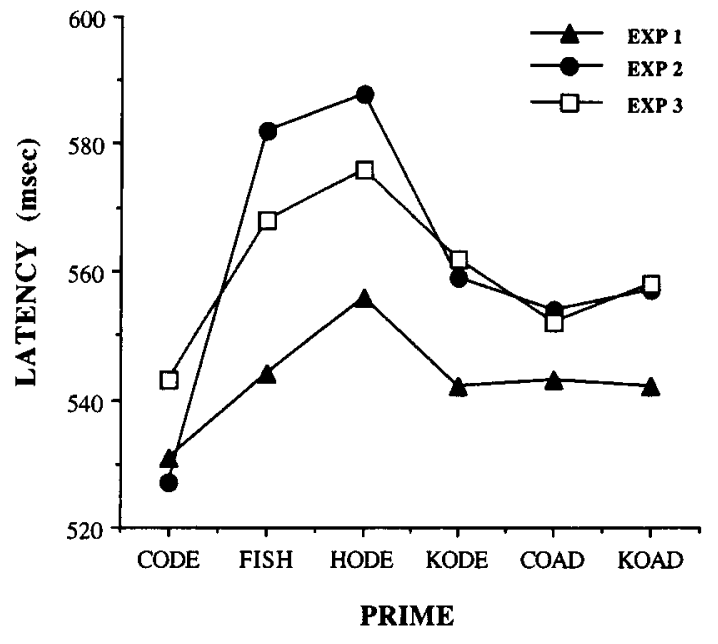

Figure 2. Target latencies following the primes of the auxiliary stimulus set for each of Experiments 1-3.

provided by the subsidiary stimulus set characterized as CODE-like primes (because CODE, KODE, COAD, KOAD, and HODE provided the paradigmatic variations). All the nonwords sharing the phonology of CODE led to faster naming (of secret) than did HODE, regardless of the number of letters (one, two, or three) by which they differed from CODE.

Experiments 2-4 were directed at phonological priming - the priming that occurs when a prime and a target are phonologically identical but not necessarily graphemically identical. Despite the contrasts in primetarget SOA ( $250 \mathrm{vs.} 34$ vs. $57 \mathrm{msec}$ ), prime identifiability, and masking sequence, the three experiments led to the same conclusions. Thus, in Experiments 2 and 3, the results with the major stimulus set revealed that priming by pseudohomophones was more pronounced and more reliable than priming by the corresponding pseudohomographs. In both of these experiments, the results with the subsidiary stimulus set (CODE-like stimuli) revealed that response latencies were reduced equivalently by one-letter, two-letters, and three-letters-different nonword homophonic primes, in comparison with an unreliable lengthening of response latency by one-letter-different nonword nonhomophonic primes. That is, phonological priming in those experiments was more pronounced than orthographic priming and seemed to be only weakly affected, if at all, by the number of letters distinguishing a pseudohomophone from the target. Within the very different stimulus presentation conditions of Experiment 4 and the restriction of the design to the direct pseudohomophone test, both one-letter-different and two-letters-different phonological primes proved more effective than their orthographic control primes. Of special note was the definite numerical (but not statistical) superiority for the one-letter-different primes over the two-letters-different primes. With respect to furthering the understanding of orthography's role within an adaptive resonance account of visual word recognition, this numerical difference ob- served in Experiment 4, together with the evidence of superior identity priming in Experiment 3, encourages pursuit of the hypothesis that crosstalk from the frequent activation of a given phonology by the letter pattern of a given word induces weight variations instantiating the orthographic-phonological correspondences at a larger grain size (approximately that of the word itself). On this hypothesis, the fewer the number of letters shared in the same position between a pseudohomophone and its corresponding word, the slower the achievement of phonological coherence by the pseudohomophone. In the context of a priming experiment, the latter outcome would mean slightly less effective priming by a two-letters-different pseudohomophone than by a one-letter-different pseudohomophone and by a one-letter-different pseudohomophone than by an identity prime, at very brief prime-target SOAs.

A complementary understanding follows from a comparison of the outcomes of Experiments 1-3. The two kinds of priming (associative in Experiment 1, phonological in Experiments 2 and 3), the priming observed at the two SOAs ( $250 \mathrm{msec}$ in Experiments 1 and 2 and $34 \mathrm{msec}$ in Experiment 3), and the priming by different pseudohomophone spellings seem to have been grounded in very similar phonologically based processes. Figure 1 compares the test primes of the major stimulus set across the three experiments, and Figure 2 compares the primes of the subsidiary stimulus set across the three experiments. As can be seen, the patterns of target latencies are alike for the conditions of pseudoassociative priming and phonological priming, for the different prime-target SOAs, and for the different spellings. ${ }^{3}$

In sum, the present data would seem to complement other data that suggest, at the very least, the need for theory to recognize early phonological constraints on visual word recognition (see, e.g., Paap, Noel, \& Johansen, 1992; Perfetti, Zhang, \& Berent, 1992) and, at the very most, the need for theory to consider that phonological constraints are foundational to visual word recognition (Bosman \& de Groot, 1996; Carello, Turvey, \& Lukatela, 1992; Frost, 1998; Liberman, 1995; Lukatela, Frost, \& Turvey, 1998; Lukatela et al., 1997; Lukatela \& Turvey, 1994a, 1994b, 1996, 1998; Van Orden, 1991). The latter foundational interpretation is expressed by the phonological coherence hypothesis: Resonance within the visual-phonological system - that is, the achievement of a coherent phonological code--is the primary mechanism for resolving the competing states of time-evolving visual-semantic and phonological-semantic interactions occurring at multiple grain sizes (Stone \& Van Orden, 1994; Van Orden \& Goldinger, 1994; Van Orden et al., 1990). Within the framework of this hypothesis, the role of orthographic codes is redefined. Rather than providing the major constraint on activating semantics (as assumed by dual-route theory), orthographic information participates in visual word recognition in more subtle and less direct ways. It facilitates, through the slower acting visual-semantic resonance, the resolution of a unique semantic pattern 
when more than one such pattern has been selected on the basis of phonology, and it influences, by virtue of weights that reflect phonology's frequent activation by word-sized orthographic patterns, the speed of visualphonological resonance. In sum, the larger promise of research such as that reported here is a deeper understanding of the interdependence of phonology and orthography in visual word recognition.

\section{REFERENCES}

Berent. I., \& Perfetti, C. A. (1995). A rose is a REEZ: The two-cycles model of phonology assembly in reading English. Psychological Review, 102, 146-184.

Bosman, A. M. T., \& de Groot, A. M. B. (1996). Phonologic mediation is fundamental to reading: Evidence from beginning readers. Quarterly Journal of Experimental Psychology, 49A, 715-744.

Carello, C., Turvey, M. T., \& Lukatela, G. (1992). Can theories of word recognition remain stubbornly nonphonological? In R. Frost \& L. Katz (Eds.), Orthography, phonology, morphology, and meaning (pp. 211-226). Amsterdam: North-Holland.

COLTHEART, M. (1978). Lexical access in simple reading tasks. In G. Underwood (Ed.), Strategies of information processing (pp. 151216). London: Academic Press.

Coltheart, M., \& Rastle, K. (1994). Serial processing in reading aloud: Evidence for dual-route models of reading. Journal of Experimental Psychology: Human Perception \& Performance, 20, 1197 1211

Davis, C., \& Forster, K. I. (1994). Masked orthographic priming: The effect of prime-target legibility. Quarterly Journal of Experimental Psychology, 47, 673-697.

Feldman, L. B., \& TuRvey, M. T. (1983). Word recognition in SerboCroatian is phonologically analytic. Journal of Experimental Psychology: Human Perception \& Performance, 9, 288-298.

FORSTER, K. I. (1987). Form-priming with masked primes: The bestmatch hypothesis. In M. Coltheart (Ed.), Attention and performance XII: The psychology of reading (pp. 127-146). Hillsdale, NJ: Erlbaum.

FORSTER, K. I. (1990). Lexical processing. In D. Osherson \& H. Lasnik (Eds.), An invitation to cognitive science: Language (pp. 95-132). Cambridge, MA: MIT Press.

Forster, K. 1., \& DAvis. C. (1991). The density constraint on formpriming in the naming task: Interference effects from a masked prime. Journal of Memory \& Language, 30, 1-25.

FROST. R. (1998). Toward a strong phonological theory of visual word recognition: True issues and false trails. Psychological Bulletin, 123, $71-99$.

Grainger, J., \& FerRand, L. (1996). Masked orthographic and phonological priming in visual word recognition and naming: Cross-talk comparisons. Journal of Memory \& Language, 35, 623-647.

Grossberg, S. (1982). Studies of mind and brain. Boston: Reidel.

Grossberg, S., \& STONE, G. O. (1986). Neural dynamics of word recognition and recall: Priming, learning, and resonance. Psychological Review, 93, 46-74

HoDGESON, J. M. (1991). Informational constraints on pre-lexical priming. Language \& Cognitive Processes, 6, 169-205.

Humphreys, G. W., EVETt, L. J., \& TAYlor, D. E. (1982). Automatic phonological priming in visual word recognition. Memory \& Cognition, 10, 576-590.

KuČera, H., \& Francis, W. N. (1967). Computational analysis of present-day American English. Providence, RI: Brown University Press.

Lesch, M. F., \& Pollatsek, A. (1993). Automatic access of semantic information by phonological codes in visual word recognition. Journal of Experimental Psvchology: Learning, Memory, \& Cognition, 19, 285-294.

LiBerman, A. M. (1995). The relation of speech to reading and writing. In B. de Gelder \& J. Morais (Eds.), Speech and reading (pp. 17-23). Hove, U.K.: Erlbaum, Taylor and Francis.
Lukatela, G., Carello, C., Savic, M., Urosevic, Z., \& Turvey, M. T. (1998). When nonwords activate semantics faster than words. Cognition, 68, B31-B40.

Lukatela, G., Frost, S., \& Turvey, M. T. (1998). Phonological priming by masked nonword primes in the lexical decision task. Journal of Memory \& Language, 39, 666-683.

LuKatela, G., Frost, S., \& TURVEY, M. T. (1999). Identity priming in English is compromised by phonological ambiguity. Journal of Experimental Psychology: Human Perception \& Performance, 25, 775790.

Lukatela, G., Savic, M., Urosevic. Z., \& Turvey, M. T. (1997). Phonological ambiguity impairs identity priming in naming and lexical decision. Journal of Memory \& Language, 36, 360-381.

Lukatela, G., \& Turvey, M. T. (1991). Phonological access of the lexicon: Evidence from associative priming with pseudohomophones. Journal of Experimental Psychology: Human Perception \& Performance, 17, 951-966.

Lukatela, G., \& Turvey, M. T. (1993). Similar attentional, frequency, and associative effects for pseudohomophones and words. Journal of Experimental Psychology: Human Perception \& Performance, 19, 166-178.

Lukatela, G., \& Turvey, M. T. (1994a). Visual lexical access is initially phonological: 1 . Evidence from associative priming by words, homophones, and pseudohomophones. Journal of Experimental Psychology: General, 123, 107-128.

Lukatela, G., \& Turvey, M. T. (1994b). Visual lexical access is initially phonological: 2 . Evidence from phonological priming by homophones and pseudohomophones. Journal of Experimental Psychology: General, 123, 331-353.

Lukatela, G., \& Turvey, M. T. (1996). Inhibition of naming by rhyming primes. Perception \& Psychophysics, 58, 823-835.

Lukatela, G., \& Turvey, M. T. (1998). Reading in two alphabets. American Psychologist, 53, 1057-1072.

lukatela, G., Turvey, M. T., Feldman, L. B., Carello, C., \& Katz, L. (1989). Alphabet priming in bi-alphabetical word perception. Journal of Memory \& Language, 28, 237-254.

NeELY, J. (1991). Semantic priming effects in visual word recognition: A selective review of current findings and theories. In D. Besner \& G. Humphreys (Eds.), Basic processes in reading: Visual word recognition (pp. 264-336). Hillsdale, NJ: Erlbaum.

PaAP, K. R., Noel, R. W., \& Johansen, L. S. (1992). Dual models of print to sound: Red herrings and real horses. In R. Frost \& L. Katz (Eds.), Orthography, phonology, morphology, and meaning (pp. 293318). Amsterdam: North-Holland.

Perfetti, C. A., Zhang, S., \& Berent, I. (1992). Reading in English and Chinese: Evidence for a "universal" phonological principle. In R. Frost \& L. Katz (Eds.), Orthography, phonology, morphology, and meaning (pp. 227-248). Amsterdam: North-Holland.

SeidenberG, M. S., Waters, G. S., SAnders, M., \& Langer, P. (1984) Pre- and postlexical loci of contextual effects on word recognition Memory \& Cognition, 12, 315-328.

Stone, G. O., \& VAN Orden, G. C. (1994). Building a resonance framework for word recognition using design and system principles. Journal of Experimental Psychology: Human Perception \& Performance, 20, 1248-1268.

UlRiCH, R., \& MilleR, J. (1994). Effects of truncation on reaction time analysis. Journal of Experimental Psychology: General, 123, 34-80.

VAn Orden, G. C. (1991). Phonologic mediation is fundamental to reading. In D. Besner \& G. Humphreys (Eds.), Basic processes in reading: Visual word recognition (pp. 77-103). Hillsdale, NJ: Erlbaum.

VAN ORden, G. C., \& Goldinger, S. D. (1994). Interdependence of form and function in cognitive systems explains perception of printed words. Journal of Experimental Psychology: Human Perception \& Performance, 20, 1269-1291.

Van Orden. G. C., Pennington, B. F., \& Stone. G. O. (1990). Word identification in reading and the promise of subsymbolic psycholinguistics. Psychological Review, 97, 488-522.

VAN SELST, M., \& JoLicoeUR. P. (1994). A solution to the effect of sample size on outlier elimination. Quarterly Journal of Experimental Psychology, 47A, 631-650. 
WARREN, R. E. (1977). Time and spread of activation in memory. Journal of Experimental Psychology: Human Learning \& Memory, 3, 458-466.

\section{NOTES}

1. Subsequent inspection revealed that eight letter strings designated as nonwords were words-BALK, BRACK, GOONS, STANK, STILE, PEAL, PEEK, and RAND. In all three experiments reported, ANOVAs were conducted with these stimuli removed, to ensure that they had not exerted a systematic effect on the main ANOVAs that were conducted on all the stimuli in Appendix A. In all the experiments, the main ANOVAs were corroborated by the ANOVAs on the truncated stimulus sets.

2. Apple Ile was used in Experiments 1-3 in order to facilitate comparisons with research done in the senior author's Belgrade laboratory, where Apple Ile computers remain the primary experimental tool.

3 . One oddity evident in the comparison of Figures 1 and 2 is the ordering of latencies by experiment. For the major set, the latencies of Experiment 1 (pseudoassociative priming) were slower than those of Experiments 2 and 3 (phonological priming); for the subsidiary set, the ordering was reversed. The source of this contrast is not obvious.

\section{APPENDIX A \\ Major Stimulus Set in Experiments 1-3}

Each row identifies, in order, the appropriate prime, the pseudohomographic prime, the pseudohomophonic prime, the dedicated nonword prime, their respective controls, and the target.

1. BAKE, BALK, BAIK, FIRG, ROPE, ROSP, ROAP, KNEX, OVEN

2. BEAM, BELM, BEEM, POUC, SHIRT, SHART, SHERT, JULLE, LIGHT

3. BIRD, BORD, BERD, NANX, LEAN, LEWN, LEEN, NATH, WING

4. BLADE, BLARD, BLAID, MOOTH, STOVE, STOOV, STOAV, KAUTH, KNIFE

5. BOAT, BOTS, BOTE, GEEF, GAME, GALM, GAIM, WOPH, SAIL

6. BREAK, BRACK, BRAIK, GITES, GROUP, GRUPH, GRUPE, YIEND, GLASS

7. BURN, BYRN, BERN, VOAX, HEAP, HERP, HEEP, DIFS, FIRE

8. DANCE, DANGE, DANSE, TRAUT, SPEAK, SPERK, SPEEK, HALGE, MUSIC

9. DATE, DAST, DAIT, RUND, GAIN, GAND, GANE, PUTH, FRIEND

10. DEAL, DERL, DEEL, NITH, ROSE, ROYE, ROZE, SHIR, CARDS

11. DEEP, DESP, DEAP, GLIS, GIRL, GARL, GURL, POPH, OCEAN

12. DINE, DENE, DYNE, ZITH, LEAP, LESP, LEEP, FOTH, EATING

13. DIRT, DORT, DERT, SCEP, LEAF, LERF, LEEF, YING, MUD

14. DOOR, DORN, DORE, PLEX, LAKE, LASK, LAIK, GOPS, KNOB

15. DREAM, DRERM, DREEM, SWALS, HORSE, HORVE, HORCE, STUTH, SLEEP

16. EAGLE, TAGLE, EEGLE, HORMS, GRIEF, GROEF, GREEF, QUALS, FLY

17. EARS, ETRS, EERS, MYPH, PEAK, PEWK, PEEK, CHIG, EYES

18. EAST, ERST, EEST, LOMB, RISE, RIKE, RIZE, JENT, WEST

19. FAIL, FALS, FALE, SPEM, JOKE, JONK, JOAK, RAUM, PASS

20. FAKE, FASK, FAIK, HOIM, ROAR, RORT, RORE, CHEG, FALSE

21. FAME, FALM, FAIM, PLUD, SOUP, SUPS, SUPE, DEMS, FORTUNE

22. FATE, FANT, FAIT, DOOG, OATS, OTLS, OTES, XEPH, DESTINY

23. FEAR, FEDR, FEER, NAWG, TYPE, TEPE, TIPE, CRED, SCARE

24. FLOOR, FLORN, FLORE, GRAXT, TRAIN, TRANK, TRANE, MEEDS, RUG

25. FOAM, FOMP, FOME, THYG, RAKE, RASK, RAIK, VEGS, BUBBLES

26. FORCE, FORNE, FORSE, SWINT, HEAT, HEYT, HEET, SHIL, PUSH

27. FRAME, FRALM, FRAIM, WHURT, SAFE, SARF, SAIF, MYDR, PICTURE

28. FRUIT, FRUTH, FRUTE, THENT, GRADE, GRALD, GRAID, KIELL, ORANGE

29. GAIN, GAND, GANE, PUTH, DATE, DAST, DAIT, RUND, LOSE

30. GAME, GALM, GAIM, WOPH, BOAT, BOTS, BOTE, GEEF, PLAY

31. GIRL, GARL, GURL, POPH, DEEP, DESP, DEAP, GLIS, BOY

32. GOAT, GOTS, GOTE, FULP, RAIL, RALS, RALE, NEPH, FARM

33. GRADE, GRALD, GRAID, KIELL, FRUIT, FRUTH, FRUTE, THENT, SCHOOL

34. GRIEF, GROEF, GREEF, QUALS, EAGLE, TAGLE, EEGLE, HORMS, SORROW

35. GROUP, GRUPH, GRUPE, YIEND, BREAK, BRACK, BRAIK, GITES, PEOPLE

36. HATE, HANT, HAIT, RUDL, SOAK, SOKL, SOKE, NECH, DISLIKE

37. HEAP, HERP, HEEP, DIFS, BURN, BYRN, BERN, VOAX, PILE

38. HEAT, HEYT, HEET, SHIL, FORCE, FORNE, FORSE, SWINT, SUMMER

39. HOME, HORM, HOAM, RELP, LATE, LANT, LAIT, GING, COMFORT

40. HOPE, HOSP, HOAP, TIGS, RATE, RAND, RAIT, THOF, HAPPINESS

41. HORSE, HORVE, HORCE, STUTH, DREAM, DRERM, DREEM, SWALS, RIDE

42. HOSE, HOYE, HOZE, NIFL, WEEP, WELP, WEAP, SHIG, WATER

43. HOUSE, HOLSE, HOWSE, KNALL, STYLE, STELE, STILE, BLOFF, FAMILY

44. HURT, HORT, HERT, CHID, PEEL, PEWL, PEAL, HOPH, PAIN

45. JAIL, JALD, JALE, FING, SOAP, SOIP, SOPE, HEEN, BARS 


\section{APPENDIX A (Continued)}

46. JOKE, JONK, JOAK, RAUM, FAIL, FALS, FALE, SPEM, LAUGH

47. LAKE, LASK, LAIK, GOPS, DOOR, DORN, DORE, PLEX, POND

48. LATE, LANT, LAIT, GING, HOME, HORM, HOAM, RELP, EARLY

49. LEAF, LERF, LEEF, YING, DIRT, DORT, DERT, SCEP, TREE

50. LEAN, LEWN, LEEN, NATH, BIRD, BORD, BERD, NANX, THIN

51. LEAP, LESP, LEEP, FOTH, DINE, DENE, DYNE, ZITH, JUMP

52. MINE, MENE, MYNE, HOYT, NEAR, NEWR, NEER, FOPS, YOURS

53. NAME, NALM, NAIM, PUNG, RAIN, RANS, RANE, YERT, PERSON

54. NEAR, NEWR, NEER, FOPS, MINE, MENE, MYNE, HOYT, CLOSE

55. NEAT, NERT, NEET, BOPH, OBEY, OBLY, OBAY, TRUN, MESSY

56. NOSE, NOGE, NOZE, DANX, YEAR, YETR, YEER, LITH, FACE

57. OATS, OTLS, OTES, XEPH, FATE, FANT, FAIT, DOOG, CEREAL

58. OBEY, OBLY, OBAY, TRUN, NEAT, NERT, NEET, BOPH, LISTEN

59. PEAK, PEWK, PEEK, CHIG, EARS, ETRS, EERS, MYPH, MOUNTAIN

60. PEEL, PEWL, PEAL, HOPH, HURT, HORT, HERT, CHID, BANANA

61. PURSE, PURDE, PURCE, LEEMS, WHEAT, WHELT, WHEET, KORCH, MONEY

62. RAIL, RALS, RALE, NEPH, GOAT, GOTS, GOTE, FULP, ROADS

63. RAIN, RANS, RANE, YERT, NAME, NALM, NAIM, PUNG, WET

64. RAKE, RASK, RAIK, VEGS, FOAM, FOMP, FOME, THYG, LEAVES

65. RATE, RAND, RAIT, THOF, HOPE, HOSP, HOAP, TIGS, EVALUATE

66. RISE, RIKE, RIZE, JENT, EAST, ERST, EEST, LOMB, SUN

67. ROAD, ROND, ROED, SENE, TEAM, TEWM, TEEM, SHUG, HIGHWAY

68. ROAR, RORT, RORE, CHEG, FAKE, FASK, FAIK, HOIM, LION

69. ROPE, ROSP, ROAP, KNEX, BAKE, BALK, BAIK, FIRG, CLIMB

70. ROSE, ROYE, ROZE, SHIR, DEAL, DERL, DEEL, NITH, FLOWER

71. SAFE, SARF, SAIF, MYDR, FRAME, FRALM, FRAIM, WHURT, SECURE

72. SAME, SARM, SAIM, GUNT, VOTE, VOIT, VOAT, WHIB, SIMILAR

73. SEAT, SELT, SEET, LORK, TURN, TARN, TERN, ZONS, CHAIR

74. SHIRT, SHART, SHERT, JULLE, BEAM, BELM, BEEM, POUC, PANTS

75. SOAK, SOKL, SOKE, NECH, HATE, HANT, HAIT, RUDL, LAUNDRY

76. SOAP, SOIP, SOPE, HEEN, JAIL, JALD, JALE, FING, BATH

77. SOUP, SUPS, SUPE, DEMS, FAME, FALM, FAIM, PLUD, CHICKEN

78. SPEAK, SPERK, SPEEK, HALGE, DANCE, DANGE, DANSE, TRAUT, TALK

79. STEAK, STANK, STAIK, BROLE, TROOP, TREPE, TRUPE, DEITH, FOOD

80. STONE, STORN. STOAN, MAIPH, TRADE, TRALD, TRAID, SHEMS, ROCK

81. STOVE, STOOV, STOAV, KAUTH, BLADE, BLARD, BLAID, MOOTH, COOK

82. STYLE, STELE, STILE, BLOFF, HOUSE, HOLSE, HOWSE, KNALL, HAIR

83. TEACH, TERCH, TEECH, GOONS, THIEF, THREF, THEEF, MOOGS, STUDENTS

84. TEAM, TEWM, TEEM, SHUG, ROAD, ROND, ROED, SENE, SPORTS

85. THIEF, THREF, THEEF, MOOGS, TEACH, TERCH, TEECH, GOONS, CROOK

86. TONE, TOON, TOAN, DURF, WAIT, WATH, WATE, HUMB, SOUND

87. TRADE, TRALD, TRAID, SHEMS, STONE, STORN, STOAN, MAIPH, ECONOMY

88. TRAIN, TRANK, TRANE, MEEDS, FLOOR, FLORN, FLORE, GRAXT, TRACKS

89. TROOP, TREPE, TRUPE, DEITH, STEAK, STANK, STAIK, BROLE, ARMY

90. TURN, TARN, TERN, ZONS, SEAT, SELT, SEET, LORK, RIGHT

91. TYPE, TEPE, TIPE, CRED, FEAR, FEDR, FEER, NAWG, WRITE

92. VOTE, VOIT, VOAT, WHIB, SAME, SARM, SAIM, GUNT, BALLOT

93. WAIT, WATH, WATE, HUMB, TONE, TOON, TOAN, DURF, STOP

94. WEEP, WELP, WEAP, SHIG, HOSE, HOYE, HOZE, NIFL, CRY

95. WHEAT, WHELT, WHEET, KORCH, PURSE, PURDE, PURCE, LEEMS, GRAIN

96. YEAR, YETR, YEER, LITH, NOSE, NOGE, NOZE, DANX, MONTH 


\section{APPENDIX B \\ Subsidiary Stimulus Set in Experiments 1-3}

Each row identifies, in order, the appropriate prime, three visually different pseudohomophonic primes (one letter different, two letters different, and three letters different), the one-letter-different nonword nonhomophonic prime, the unrelated word prime, and the target word.

1. CAKE, KAKE, CAIK, KAIK, JAKE, DIES, SWEET

2. CANE, KANE, CAIN, KAIN, ZANE, DEAF, WALKING

3. CARE, KARE, CAIR, KAIR, YARE, REST, LOVE

4. CAVE, KAVE, CAIV, KAIV, ZAVE, WEPT, DARK

5. CLAIM, KLAIM, CLAME, KLAME, SLAMM, TREES, LUGGAGE

6. CLOVE, KLOVE, CLOAV, KLOAV, SLOVE, PUFF,, SPICE

7. COAL, KOAL, COLE, KOLE, WOLE, KIDS, BLACK

8. COAT, KOAT, COTE, KOTE, FOAT, TEND, JACKET

9. CODE, KODE, COAD, KOAD, HODE, FISH, SECRET

10. COKE, KOKE, COAK, KOAK, DOKE, WRAP, SODA

11. CONE, KONE, COAN, KOAN, RONE, BLEW, ICE CREAM

12. COPE, KOPE, COAP, KOAP, WOPE, GRIP, HANDLE

13. CORE, KORE, COAR, KOAR, NORE, PLOT, APPLE

14. COVE, KOVE, COAV, KOAV, YOVE, SIRS, HARBOR

15. CRANE, KRANE, CRAIN, KRAIN, WRANE, PUNCH, MACHINE

16. CRATE, KRATE, CRAIT, KRAIT, PRATE, MASTS, BOX

17. CRAVE, KRAVE, CRAIV, KRAIV, WRAVE, MIRTH, DESIRE

18. CREAM, KREAM, CREEM, KREEM, FREAM, NOBLE, COFFEE

19. CROAK, KROAK, CROKE, KROKE, TROAK, BOLTS, DIE

20. SCALE, SKALE, SCAIL, SKAIL, SPALE, RIFLE, WEIGHT

21. SCARE, SKARE, SCAIR, SKAIR, SLARE, GRITS, FRIGHTEN

22. SCOPE, SKOPE, SCOAP, SKOAP, SNOPE, TIGHT, VIEW

23. SCORE, SKORE, SCOAR, SKOAR, SLORE, TESTS, POINTS

24. SKATE, SCATE, SKAIT, SCAIT, SMATE, LUCKS, ROLLER

\section{APPENDIX C \\ Stimulus Materials in Experiment 4 Constructed From the CLIP-Like Words}

Each row identifies, in order, the homophonic prime, the orthographic control prime, and the corresponding target.

1. KORK, NORK, CORK

2. KORD, PORD, CORD

3. KOINS, DOINS, COINS

4. KRISP, TRISP, CRISP

5. KLERK, PLERK, CLERK

6. KLOCK, SLOCK, CLOCK

7. KREEK, PREEK, CREEK

8. KATCH, RATCH, CATCH

9. KARD, PARD, CARD

10. KAPS, WAPS, CAPS

11. KLUE, PLUE, CLUE

12. KLING, PLING, CLING

13. KLAM, FLAM, CLAM

14. KANS, ZANS, CANS

15. KREW, FREW, CREW

16. KASE, ZASE, CASE

17. KOST, DOST, COST

18. KROSS, TROSS, CROSS

19. KAGE, LAGE, CAGE

20. KOACH, MOACH, COACH

21. KRUDE, DRUDE, CRUDE

22. KARS, YARS, CARS

23. KRAFT, PRAFT, CRAFT

24. KLOUD, FLOUD, CLOUD 


\begin{tabular}{cl} 
APPENDIX C (CONtinUed) \\
\hline 25. & KOLD, DOLD, COLD \\
26. & KROWN, WROWN, CROWN \\
27. & KRAB, FRAB, CRAB \\
28. & KART, YART, CART \\
29. & KRACK, DRACK, CRACK \\
30. & KLUMP, FLUMP, CLUMP \\
31. & KRASH, PRASH, CRASH \\
32. & KLIFF, SLIFF, CLIFF \\
33. & KLIP, PLIP, CLIP \\
34. & KULT, YULT, CULT \\
35. & KREED, TREED, CREED \\
36. & KROP, WROP, CROP \\
37. & KOPS, YOPS, COPS \\
38. & KAMP, ZAMP, CAMP \\
39. & KORN, NORN, CORN \\
40. & KOURT, NOURT, COURT \\
41. & KATS, YATS, CATS \\
42. & KLUB, FLUB, CLUB \\
43. & KLAY, BLAY, CLAY \\
44. & KUTS, VUTS, CUTS \\
45. & KUPS, NUPS, CUPS \\
46. & KRIB, FRIB, CRIB \\
47. & KAST, YAST, CAST \\
48. & KREST, FREST, CREST \\
&
\end{tabular}

\section{APPENDIX D}

\section{Stimulus Materials of Experiment 4}

\section{Constructed From the HEAT-Like Words}

Each row identifies, in order, the homophonic prime, the orthographic control prime, and the corresponding target.
1. BEAF, BEEK, BEEF
2. BEED, BERD, BEAD
3. BLEAD, BLERD, BLEED
4. BLEEK, SLEAK, BLEAK
5. BOYL, BOAL, BOIL
6. CAUZE, CAUTE, CAUSE
7. CEEK, MEEK, SEEK
8. CHEAK, CHEET, CHEEK
9. CHEET, CHEAK, CHEAT
10. CIDE, LIDE, SIDE
11. CREAP, CHEEP, CREEP
12. DETT, DELT, DEBT
13. FEAD, FEEZ, FEED
14. GAWZE, GAIZE, GAUZE
15. HAUK, HAWL, HAWK
16. HEET, HERT, HEAT
17. HERT, HART, HURT
18. HOYST, HAIST, HOIST
19. JERM, FERM, GERM
20. KEAL, KERL, KEEL
21. KEAN, MEEN, KEEN
22. KREAM, CROAM, CREAM
23. KRIME, PRIME, CRIME
24. KYTE, KOTE, KITE
25. LEEF, REAF, LEAF
26. NEAD, NEEL, NEED
27. PAKT, PECT, PACT
28. PAUZE, PAUNE, PAUSE
29. RAYD, RAIT, RAID
30. REAF, REEP, REEF 


\begin{tabular}{cl}
\hline 31. & REEP, ROAP, REAP \\
32. & RHIME, RHYTE, RHYME \\
33. & SEAD, SEET, SEED \\
34. & SEAP, SEEL, SEEP \\
35. & SEASE, GEASE, CEASE \\
36. & SEET, SEAD, SEAT \\
37. & SOAL, SOYL, SOUL \\
38. & SOYL, SOAL, SOIL \\
39. & STEAP, STEEM, STEEP \\
40. & STEEM, STEAP, STEAM \\
41. & TAYL, TAIP, TAIL \\
42. & TEATH, TEECH, TEETH \\
43. & TEAZE, TEAME, TEASE \\
44. & TEECH, TEATH, TEACH \\
45. & TIPE, TYDE, TYPE \\
46. & TRAYL, TRAUL, TRAIL \\
47. & TYDE, TODE, TIDE \\
48. & WHEAL, WREEL, WHEEL \\
\hline
\end{tabular}

\section{APPENDIX E}

Stimulus Materials in Experiment 4 Constructed From the NAME-Like Words

Each row identifies, in order, the homophonic prime, the orthographic control prime, and the corresponding target.

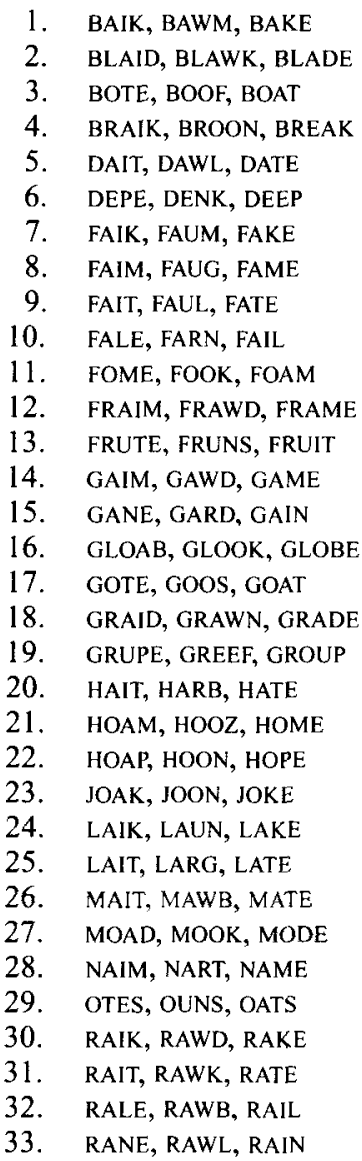


APPENDIX E (Continued)

34. ROAP, ROON, ROPE

35. RORE, ROOL, ROAR

36. SAIF, SART, SAFE

37. SAIM, SAUP, SAME

38. SOKE, SOOM, SOAK

39. SOPE, SOOK, SOAP

40. STAIK, STOWN, STEAK

41. STOAN, STOOK, STONE

42. STOAV, STOOK, STOVE

43. TOAN, TOOM, TONE

44. TRAID, TRAWN, TRADE

45. TRANE, TRAWB, TRAIN

46. TRUPE, TREAF, TROOP

47. VOAT, VOOL, VOTE

48. WATE, WARF, WAIT

(Manuscript received November 10, 1997;

revision accepted for publication September 27, 1998.) 